NASA Technical Memorandum 100176

\title{
Composite Mechanics for Engine Structures
}

\author{
(NASA-TM-100176) CCMECSITE MECHANTCS FOR \\ ENGINE STEUCTURES (NASA) 3E P CSCL 11D \\ $N 88-12552$ \\ Unclas \\ G3/24 0111326
}

Christos C. Chamis

- Lewis Research Center

Cleveland, Ohio

Prepared for the

32nd International Gas Turbine Conference and Exhibition sponsored by the American Society of Mechanical Engineers Anaheim, California, May 31-June 4, 1987 


\section{COMPOSITE MECHANICS FOR ENGINE STRUCTURES}

Christos C. Chamis

National Aeronautics and Space Administration

Lewis Research Center

Cleveland, Ohio 44135

\section{SUMMARY}

Recent research activities and accomplishments at Lewis Research Center on composite mechanics for engine structures are reviewed in summary form. The activities mainly focused on developing procedures for the computational simulation of composite intrinsic and structural behavior. The computational simulation encompasses all aspects of composite mechanics, advanced threedimensional finite-element methods, damage tolerance, composite structural and dynamic response, and structural tailoring and optimization.

\section{INTRODUCTION}

The application of composites in engine structures offers a multitude of advantages to the use of metals. These advantages include high stiffness, light weight, improved fatigue, higher damping, reduced number of fabricated parts, reduced number of joints, and minimum or no final machining. Disadvantages include a larger number of thermal and mechanical properties, low impact resistance, low damage tolerance, limited engineering data base, and more complex analyses. The complex analyses are conventionally referred to as composite mechanics. Continuing research activities at Lewis Research Center have led to significant developments in composite mechanics for application to engine structures. The objective of this report is to describe recent research activities and accomplishments in composite mechanics for fiber-reinforced, polymer-matrix composites.

These activities included research in all aspects of composite mechanics, advanced finite-element methods, composite fracture, and structural tailoring. 
Each research activity focused on (1) capturing the physics of composite behavior at the level of interest, (2) developing an appropriate mathematical model, and (3) developing the respective computer code for the computational simulation. Specifically, these items include (1) integrated composite mechanics analysis and the integrated composite analyzer (ICAN) computer code, (2) simplified composite mechanics for strength, (3) three-dimensional finite-element for micromechanics, (4) composite fracture toughness and progressive fracture, (5) local interlaminar damage, (6) passive damping, and (7) structural tailoring. Each of these is described in summary form with illustrative examples and brief discussions on implications for practical applications. Symbols used in the report are defined in the appendix. Relevant references are cited for additional details and for comparison with available data.

\section{INTEGRATED COMPOSITE MECHANICS}

The development of composite mechanics encompasses al1 aspects from micromechanics to laminate theory. Parts of the composite mechanics also include stress concentrations due to open holes, free-edge interlaminar stresses, laminate failure, and hygrothermal environmental effects. One way to integrate all these aspects of composite mechanics is to include them in a modular, open-ended, user-friendly computer code. A computer code of this type, identified as ICAN for Integrated Composite Analyzer, has been developed. Both stand-alone and portable, ICAN is based on constituent material properties which are available in a resident data bank. Additional features of ICAN are its capability to handle hybrids, both intraply and interply, and the inclusion of the interply layer as a distinct matrix layer.

The integrated analysis capability of ICAN is depicted schematically in Figure 1. A flowchart and a portion of the input data are shown in Figure 2 . This version of ICAN has been documented (theory and users manual) in 
References 1 and 2 and is available through COSMIC (contact COSMIC, The University of Georgia, Athens, GA 30602, concerning the availability of this program). Representative results predicted by ICAN are shown in Figure 3 , and comparisons with measured data are given in Table I (Ref. 3). The computer code ICAN is available to perform the various composite mechanics that may be required for the analysis of composite structures for propulsion systems.

\section{SIMPLIFIED MICROMECHANICS FOR STRENGTH}

The development of composite mechanics has often led to derivations of simplified sets of equations for predicting specific composite properties. These sets of equations are useful because all the participating variables, their relationships to each other, and their significance and contribution to the specific composite property are readily observed. A set of this type was developed for predicting ply uniaxial strengths by using respective constituent properties. A part of this set is summarized in Figure 4 . The various strengths are readily identifiable. The required inputs to the equations and their respective outputs are summarized in the block diagram of figure 4 . As shown, fabrication process variables (fiber and void volume ratios) and environmental effects (temperature and moisture) are accounted for in these equations. This set of equations is described in detail in Reference 4, where numerical examples and comparisons with measured data are also included.

A similar set of simplified equations was developed for ply microstresses. This set includes all the equations required to predict and assess the microstresses (stress in the matrix, fiber, and interface) when the ply stresses are known or have been determined by using laminate theory. The concept, procedure, and locations are illustrated schematically in Figure 5 . The subset of equations for predicting the microstresses due to ply transverse stress are summarized in Figure 6 . Results predicted by using these equations when the applied ply transverse stress is equal to transverse (1) tensile and 
(2) compressive strength are summarized in figure 7 . The remaining parts of the set for predicting ply microstresses due to other ply stresses and due to temperature and moisture are described in detail in Reference 5. In summary, the development of composite mechanics also includes simplified equations which describe complex composite behavior in relatively simple form. Each set of the se equations is a module in ICAN.

\section{THREE-DIMENSIONAL FINITE-ELEMENT MODELING}

Parallel developments in composite mechanics include three-dimensional finite-element modeling of composite behavior at the micromechanics scale. There are several reasons for this type of modeling, two of which are (1) validation of simplified equations and (2) more detailed evaluation of micromechanistic behavior. Results predicted from a specific three-dimensional finite-element model to validate simplified micromechanics equations are summarized in Figure 8, where these results are compared with those predicted by the respective simplified equations. Similar comparisons for other properties are summarized in Reference 6 . The modeling procedure is described in detail in Reference 7 . Two of the properties plotted in Figure 8 (shear modulus $G_{\ell 23}$ and Poisson's ratio v) are rather difficult to predict and very difficult (if not impossible) to measure. In this respect, three-dimensional finite-element modeling is the only practical means available.

The type of three-dimensional finite-element model shown in Figure 8 , referred to as superelement, is readily adaptable to investigating the effects of interfacial bonds, disbonds, fiber breaks, voids, and even matrix cracks on the microstress distribution. In addition, stresses due to temperature and moisture can also be studied. It suffices to say that composite behavior at the micromechanics scale can be studied and described in detail by using three-dimensional finite-element modeling and analysis methods. 
Another form of three-dimensional finite-element modeling is used to evaluate the interlaminar stress field near free edges of angleplied laminates. This form is usually referred to as progressive finite-element substructuring. The concept and models are schematically illustrated in Figure 9 with typical results for a specific laminate. The details of the procedure are described in Reference 8 , which includes similar results for other laminates. It is interesting to note that interlaminar stress fields near free edges may initiate fracture, especially under cyclic loads, which predominate in propulsion structural systems.

COMPOSITE FRACTURE TOUGHNESS AND PROGRESSIVE FRACTURE

In addition to other design requirements, composite structures are designed to be damage tolerant. Damage tolerance usually refers to the ability of the structural component to sustain, without repairs, a specified level of preexisting inadvertent damage (defects) for the designed load conditions and service life. The ability of the material to be damage tolerant is usually measured by its fracture toughness, which is characterized by two parameters: (1) a defect size (crack length) and (2) a stress-intensity field which will rapidly propagate the defect to fracture. The fracture toughness of a material is generally determined experimentally. One of the convenient experimental methods to determine the fracture toughness of a material is the strain energy release rate (SERR).

Recent research at Lewis led to the development of a versatile computational procedure to determine the interlaminar SERR of composite structures. This procedure, described in detail in References 9 and 10, is summarized in Figure 10. A loading schematic is shown in Figure 11, and representative results are shown in Figure 12, where SERR's for each fracture mode are plotted as functions of crack length for different angleplied composite laminates. 
The computational procedure can be readily used to assess composite critical parameters such as fiber volume ratio, as shown in Figure 13. This type of computational procedure provides an indirect but representative method for evaluating the damage tolerance of candidate structural design concepts with available advanced composite materials and with emerging ones which are only available in small laboratory quantities.

A directly related and more fundamental research activity is the computational simulation of progressive fracture in composite structures. This procedure tracks the participating fracture modes within the different scales (micromechanics and constituents, macromechanics, ply, laminate, local, and global) in a composite structure. The procedure is described in Reference 11. Some representative results at select scales are (1) detailed fracture modes at the micromechanics level (Table II), (2) intralaminar shear stresses at the ply level (Fig. 14), (3) predominate fracture modes at the 10cal level (Fig. 15), and (4) photomicrographs showing attendant fracture surface characteristics (Fig. 16). It suffices to say that computational procedures can be developed to simulate progressive fracture in propulsion composite structures by tracking participating fracture modes at the various scales in which they occur.

\section{LOCAL DAMAGE EFFECTS ON GLOBAL STRUCTURAL RESPONSE}

Damage tolerance of composites (especially that are due to impact) can also be evaluated by comparing the global structural response of undamaged and damaged composite structures. The type of damage induced is described by the user, depending on the specific design requirements. For example, the interlaminar damage tolerance of composite cantilevers is shown in Figure 17 in terms of two global variables: (1) displacement and (2) frequencies (Ref. 12). The global variable is plotted as a function of extent of the delamination, as shown in the schematics. The results shown in Figure 17 are interesting 
because they demonstrate that considerable relative damage must be present prior to significant changes (greater than 15 percent) in global structural response.

One practical implication of these results is that field inspection methods based on global structural response will not be generally successful in detecting relatively small changes (about 10 percent) in delamination-type damage. Higher vibration modes need to be examined. More precisely, the half wavelength of the vibration mode should approach the damage length (mode 4 and greater in Fig. $17(\mathrm{c})$ ). Composite mechanics computational simulation can be used to evaluate the effect of local damage on global structural response and also to assess the sensitivity of field inspection nondestructive-evaluation techniques.

\section{PASSIVE DAMPING EFFECTS}

Applications of composites to engine fan blades or advanced turboprops subject the composites to a broad range of excitation (forced vibration) sources and subsequent fatigue. The conventional practice is to design the composite blade or turboprop to avoid the frequencies of the excitation sources, at least in the operating range. Since composite blades and turboprops are made by stacking and bonding multiple layers, it is natural to consider passive damping to minimize or dampen the effects of the anticipated and unanticipated excitation sources. The passive damping can be implemented in terms of either interplied or constrained adhesive layers.

The effects of passive damping on vibration modes can be readily evaluated, and thereby desirable material damping characteristics can be identified by using composite mechanics and forced-response finite-element analyses. The computational procedure is described in detail in Reference 13. A composite turboprop is illustrated in Figure 18, and some representative 
results with possible applications to composite turboprops are shown in Figure 19. As shown in Figure 19, the amount of damping of the vibration mode amplitude can be determined, and the adhesive layer material characteristics necessary to provide this damping can be identified as functions of modulus and shear stress.

STRUCTURAL TAILORING OF COMPOSITE BLADES

Composite blade structural design requires the integration of several relevant disciplines, including (1) composite mechanics, (2) structural analysis, (3) fatigue, (4) flutter, (5) impact, (6) thermal stress analysis, and (7) overall costs, which include material, fabrication, operation, maintenance, and profits. Each of the disciplines is usually handled by a different individual or group specializing in that discipline. The discipline task is performed sequentially by using appropriate inputs from the other disciplines. The process usually requires several time-consuming iterations to obtain a satisfactory design. An effective alternative is to integrate the various participating disciplines and the specified design requirements into a formal structural optimization computer code.

Research conducted by Lewis Research Center during the recent past led to the development of the computer code STAEBL (Structural Tailoring of Engine Blades), as described in References 14 to 16 . The essential features/modules of STAEBL are summarized schematically in Figure 20. Additional features and a schematic of the model produced by the dedicated finite-element module in STAEBL are shown in Figure 21. Typical results obtained are shown in Table III. STAEBL, proven to be very effective for the design of engine blades, is presently being extended for turboprops which have complex internal configurations (Fig. 18). In addition, STAEBL has been extended to include simultaneous tailoring for aerodynamic and structural considerations, and it 
has also been used to obtain designs in several situations where the conventional approach did not succeed. In all these situations, professional and computer times required were substantially (in orders of magnitude) reduced. The multi-disciplinary design process of complex engine composite structures has been computationally simulated and integrated by using structural tailoring and optimization concepts and methods.

CONCLUDING REMARKS

Continuing research at Lewis Research Center in composite mechanics for engine structures has led to significant developments in all aspects of composite mechanics and has resulted in computer codes for respective computational simulations. These include (1) integrated composite mechanics analyzer (ICAN), (2) simplified composite micromechanics for strength, (3) threedimensional finite-element modeling/superelement for composite micromechanics, (4) composite fracture toughness and progressive fracture, (5) local interlaminar damage effects on global structural response, (6) passive damping effects, and (7) structural tailoring of composite blades (STAEBL). Each of these are briefly reviewed and summarized with representative examples. The brief summaries and the illustrative examples included demonstrate that the structural response of complex engine components can be computationally simulated at all levels of composite mechanics. In addition, the multidisciplinary design process of composite blades can be integrated into structural tailoring/optimization codes which result in significant professional and computer time savings. 
APPENDIX - SYMBOLS

a

d

E

G

$\mathrm{G}_{\mathrm{T}}$

k

M

P

S

T

$t$

$u, v, w$

$x_{r}$

$x, y, z$

r

$v$

$\sigma$

$1,2,3$

I, II, III crack length

diameter

elastic modulus

shear modulus

total strain energy release rate

volume ratio

moisture

load

strength

temperature

thickness

displacements

free-edge distance

structural reference axes

ply angle orientation

Poisson's ratio

stress

ply material axes

Subscripts:

B

C

C

F

f

i

$\ell$ beam

compression

composite property

flexural

fiber

interface

ply

10 
m

n

$S$

5

T

u

v

$x, y, z$

$1,2,3$

matrix

normal to interface

shear

symmetric, shear tangential to interface (Fig. 7)

tension

use

void

Superscripts:

A

microstress in intermatrix subregion $A$

B

microstress in interfiber subregion $B$

C

microstress in the interface in intermatrix subregion $C$ 


\section{REFERENCES}

1. Murthy, P.L.N. and Chamis, C. C., "Integrated Composite Analyser (ICAN). Users and Programmers Manual," NASA TP-2515, 1986.

2. Murthy, P.L.N. and Chamis, C.C., "ICAN Integrated Composite Analyzer," Journal of Composites Technology and Research, Vol. 8., No. 1, Spring 1986, pp. 8-17.

3. Ginty, C.A. and Chamis, C.C., "Select Fiber Composites for Space Applications: A Mechanistic Assessment," Technology Vectors, SAMPE, Azusa, CA, 1984, pp. 979-993. (NASA TM-83631).

4. Chamis, C.C., "Simplified Composite Micromechanics Equations for Strength, Fracture Toughness, and Environmental Effects," SAMPE Quarterly, Vol. 15, No. 4, 1984, pp. 41-55. (NASA TM-83696).

5. Chamis, C.C., "Simplified Composite Micromechanics for Predicting Microstresses," NASA TM-87295, 1986.

6. Caruso, J.J. and Chamis, C.C., "Assessment of Simplified Composite Micromechanics Using Three-Dimensional Finite-Element Analysis, "Journal of Composites Technology and Research, Vol. 8, No. 3, Fall 1986, pp. 77-83.

7. Caruso, J.J., "Application of Finite Element Substructuring to Composite Micromechanics," NASA TM-83729, 1984.

8. Murthy, P.L.N. and Chamis, C.C., "A Study of Interply Layer Effects on the Free Edge Stress Field of Angleplied Laminates," Computers and Structures, Vol. 20, No. 1-3, 1985, pp. 431-441. (NASA TM-86924).

9. Murthy, P.L.N. and Chamis, C.C., "Interlaminar Fracture Toughness: Three-Dimensional Finite-Element Modeling for End-Notch and Mixed-Mode Flexure," NASA TM-87138, 1985.

10. Murthy, P.L.N. and Chamis, C.C., "Composite Interlaminar Fracture Toughness: Three-Dimensional Finite Element Modeling for Mixed Mode I, II and III Fracture," NASA TM-88872, 1986. 
11. Chamis, C.C., "Computational Simulation of Progressive Fracture in Fiber Composites," NASA TM-87341, 1986.

12. Grady, J.E. and Sun, C.T., "Dynamic Delamination Crack Propagation in a Graphite/Epoxy Laminate," Composite Materials: Fatigue and Fracture, H. T. Hahn, ed., ASTM STP-907, ASTM, Philadelphia, 1986, pp. 5-31.

13. Chamis, C.C. and Williams, G.L., "Interply Layer Degradation Effects on Composite Structural Response," Journal of Aircraft, Vol. 22, No. 7, July 1985, pp. 573-580. (NASA TM-83702).

14. Platt, C.E., Pratt, T.K., and Brown, K.W., "Structural Tailoring of Engine Blades (STAEBL)," NASA CR-167949, 1982.

15. Brown, K.W., "Structural Tailoring of Engine Blades (STAEBL) - Theoretical Manual," NASA CR-175112, 1986.

16. Brown, K.W., "Structural Tailoring of Engine Blades (STAEBL) - User's Manual," NASA CR-175113, 1986.

TABLE I. - REPRESENTATIVE DATA FOR VARIOUS USE TEMPERATURES $T_{u}$ PREDICTED BY INTEGRATED COMPOSITE ANALYZER

(ICAN) COMPARED WITH EXPERIMENTAL DATA

\begin{tabular}{|l|c|c|c|c|c|c|}
\hline \multirow{2}{*}{ Material } & \multicolumn{5}{|c|}{ Longitudinal elastic modulus, ksi } \\
\cline { 2 - 7 } & \multicolumn{2}{|c|}{$T_{u}=-300^{\circ} \mathrm{F}$} & \multicolumn{2}{|c|}{$T_{u}=70^{\circ} \mathrm{F}$} & \multicolumn{2}{|c|}{$T_{u}=200{ }^{\circ} \mathrm{F}$} \\
\cline { 2 - 7 } & ICAN & Measured & ICAN & Measured & ICAN & Measured \\
\hline Composite 1a & 4589 & 4679 & 4251 & 4357 & 4076 & 4107 \\
Composite 2b & 5587 & 6643 & 5395 & 5964 & 5457 & 5981 \\
Composite 3c & 4440 & 5300 & 4114 & 4300 & 3948 & 4200 \\
\hline
\end{tabular}

a 7781 E-glass cloth.

b7576 E-glass cloth.

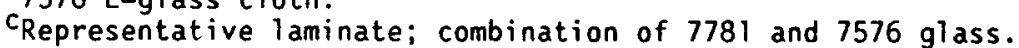


TABLE II. - FRACTURE MODES OF $[ \pm \theta]_{S}$ GRAPHITE/EPOXY LAMINATES PREDICTED BY COMPOSITE DURABILITY

STRUCTURAL ANALYSIS (CODSTRAN)

[Longitudinal tension, LT; transverse tension, TT; intraply shear, $S$; and intraply delamination, I.]

\begin{tabular}{|c|c|c|c|}
\hline \multirow{2}{*}{$\begin{array}{c}\text { Ply } \\
\text { orientation, } \\
\theta, \\
\text { deg }\end{array}$} & \multicolumn{3}{|c|}{ Fracture mode } \\
\hline & $\begin{array}{l}\text { Unnotched } \\
\text { solid } \\
\text { specimen }\end{array}$ & $\begin{array}{l}\text { Notched } \\
\text { specimen, } \\
\text { with slit }\end{array}$ & $\begin{array}{l}\text { Notched } \\
\text { specimen, } \\
\text { with hole }\end{array}$ \\
\hline 0 & LT & $\begin{array}{l}S^{a} \\
\text { LT }\end{array}$ & $\begin{array}{l}S^{\alpha} \\
L T\end{array}$ \\
\hline 3 & $\begin{array}{l}\mathrm{LT} \\
\mathrm{S}^{\mathrm{b}}\end{array}$ & $\begin{array}{l}S^{a} \\
L T\end{array}$ & $\begin{array}{l}S^{\alpha} \\
L T\end{array}$ \\
\hline 5 & $\begin{array}{l}\text { LT } \\
S^{b}\end{array}$ & $\begin{array}{l}\mathrm{S}^{\mathrm{a}} \\
\mathrm{LT}\end{array}$ & $\begin{array}{l}S^{a} \\
\text { LT }\end{array}$ \\
\hline 10 & $\begin{array}{l}\mathrm{LT} \\
\mathrm{S}^{\mathrm{b}}\end{array}$ & $S$ & $S$ \\
\hline 15 & $\begin{array}{l}\text { I } \\
\text { S }\end{array}$ & $S$ & $\begin{array}{l}\mathrm{S} \\
\mathrm{LT}\end{array}$ \\
\hline 30 & $S$ & $\begin{array}{l}I^{C} \\
S\end{array}$ & $\begin{array}{l}\mathrm{I}^{\mathrm{C}} \\
\mathrm{S}\end{array}$ \\
\hline 45 & $\begin{array}{l}\text { I } \\
\text { S }\end{array}$ & $\begin{array}{l}I^{C} \\
S\end{array}$ & $\begin{array}{l}\mathrm{I}^{\mathrm{C}} \\
\mathrm{S} \\
\mathrm{TT}\end{array}$ \\
\hline 60 & TT & $\begin{array}{l}\mathrm{I}^{\mathrm{C}} \\
\mathrm{TT} \\
\mathrm{S}^{\mathrm{d}}\end{array}$ & $\begin{array}{l}\mathrm{I}^{\mathrm{C}} \\
\mathrm{TT}\end{array}$ \\
\hline 75 & TT & TT & TT \\
\hline 90 & $T T$ & $T T$ & TT \\
\hline
\end{tabular}

anitial fracture due to intraply shear in notchtip zone.

bSome intraply shear occurring near constraints (grips).

CDelaminations occur in notch-tip zone prior to any intraply damage.

dMinimal intraply shearing during fracture. 
TABLE III. - EFFECT OF PRESSURE AND THERMAL LOADS ON OPTIMUM BLADE DESIGN

\begin{tabular}{|c|c|c|c|c|c|c|}
\hline & \multicolumn{3}{|c|}{$\begin{array}{l}\text { Pressure } \\
\text { load }\end{array}$} & \multicolumn{3}{|c|}{$\begin{array}{l}\text { Pressure and } \\
\text { thermal loads }\end{array}$} \\
\hline & \multicolumn{3}{|c|}{ Span, percent } & \multicolumn{3}{|c|}{ Span, percent } \\
\hline & 0 & 50 & 100 & 0 & 50 & 100 \\
\hline $\begin{array}{l}\text { Thickness, in. } \\
\text { Chord, in. } \\
\text { Thickness-to- } \\
\text { chord ratio }\end{array}$ & $\begin{array}{r}0.47 \\
3.33 \\
.14\end{array}$ & $\begin{array}{r}0.08 \\
3.66 \\
.02\end{array}$ & $\begin{array}{r}0.10 \\
4.22 \\
.02\end{array}$ & $\begin{array}{r}0.48 \\
3.27 \\
.14\end{array}$ & $\begin{array}{r}0.08 \\
3.60 \\
.02\end{array}$ & $\begin{array}{r}0.08 \\
4.15 \\
.02\end{array}$ \\
\hline $\begin{array}{l}\text { Weight, } 1 \mathrm{~b} \text {. } \\
\text { Constraints } \\
\text { Resonance margin } \\
\text { Mode I } \\
\text { Mode II } \\
\text { Mode III } \\
\text { Flutter constraint } \\
\text { Root stress }\end{array}$ & \multicolumn{3}{|c|}{$\begin{array}{l}0.05 \\
1.55 \\
1.71 \\
.510 \\
.782\end{array}$} & \multicolumn{3}{|c|}{$\begin{array}{l}0.05 \\
1.47 \\
1.67 \\
.520 \\
.813\end{array}$} \\
\hline
\end{tabular}

Temperature-dependent properties.

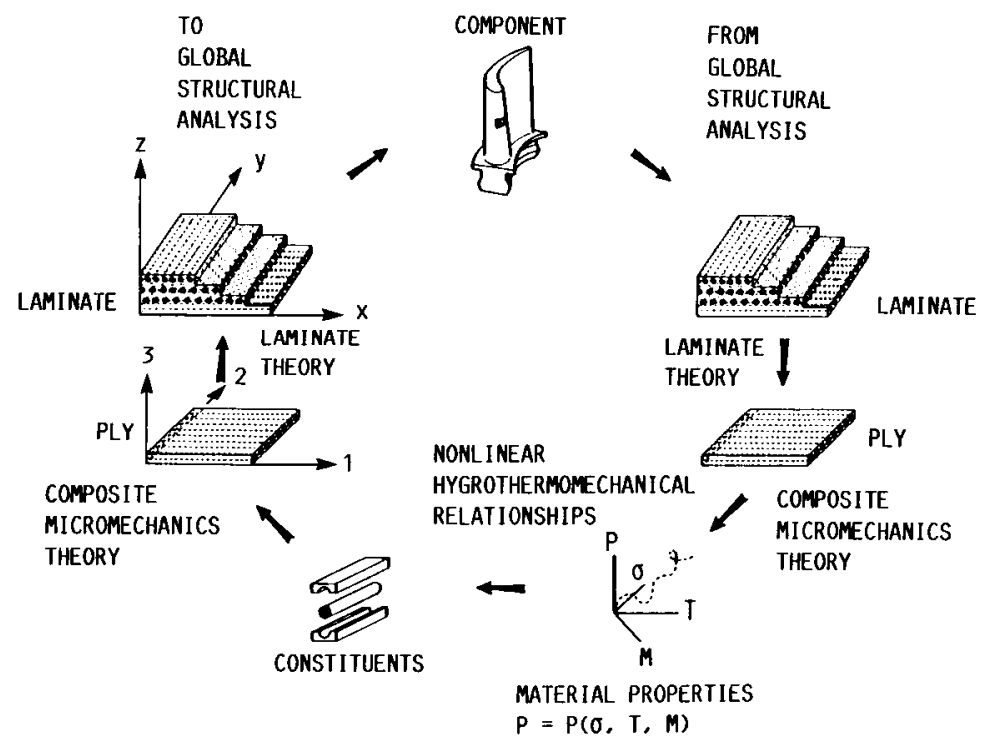

FIGURE 1. - ANALYSIS CAPABILITY OF INTEGRATED COMPOSITE ANALYZER (ICAN). 


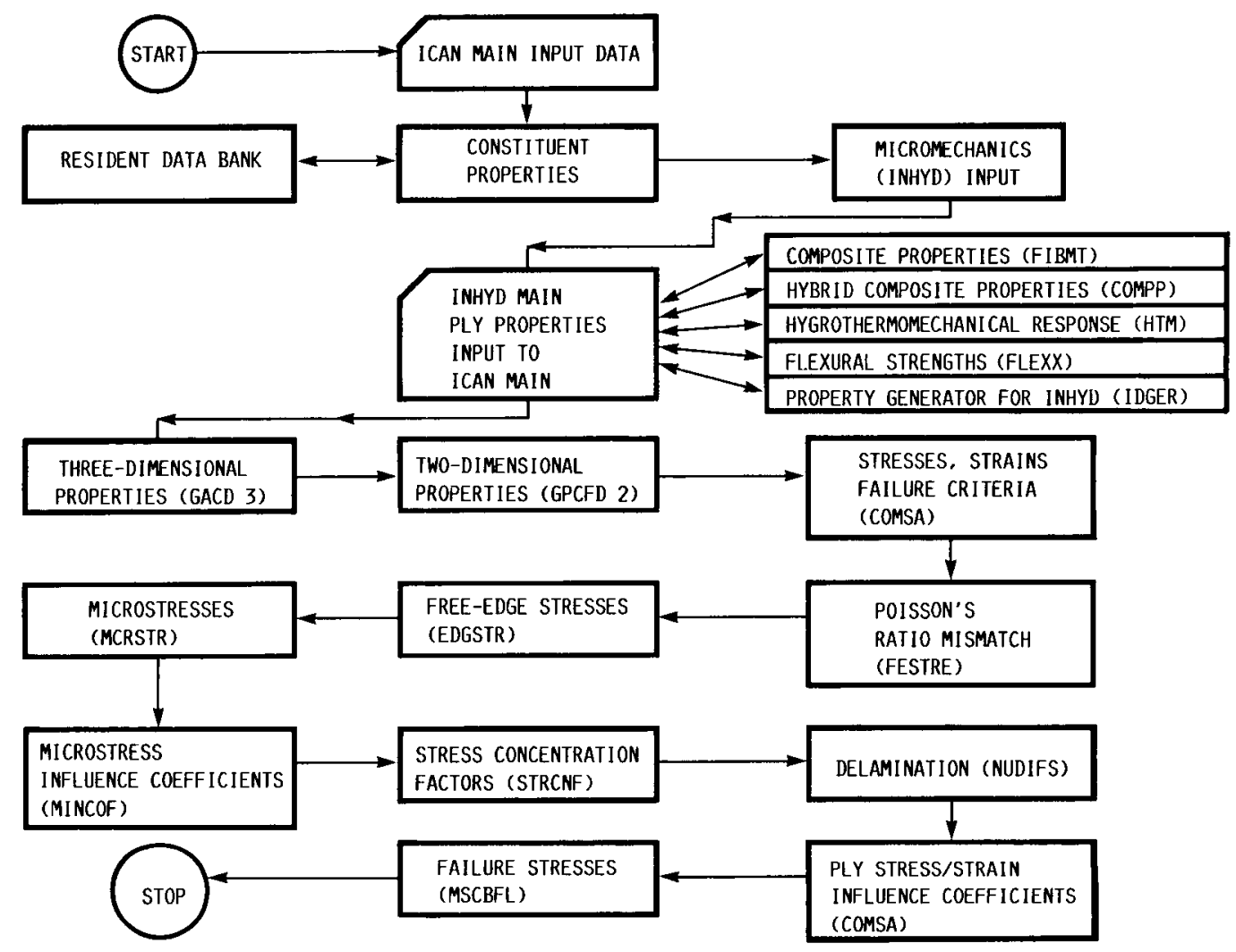

(A) ICAN FLOW CHART.

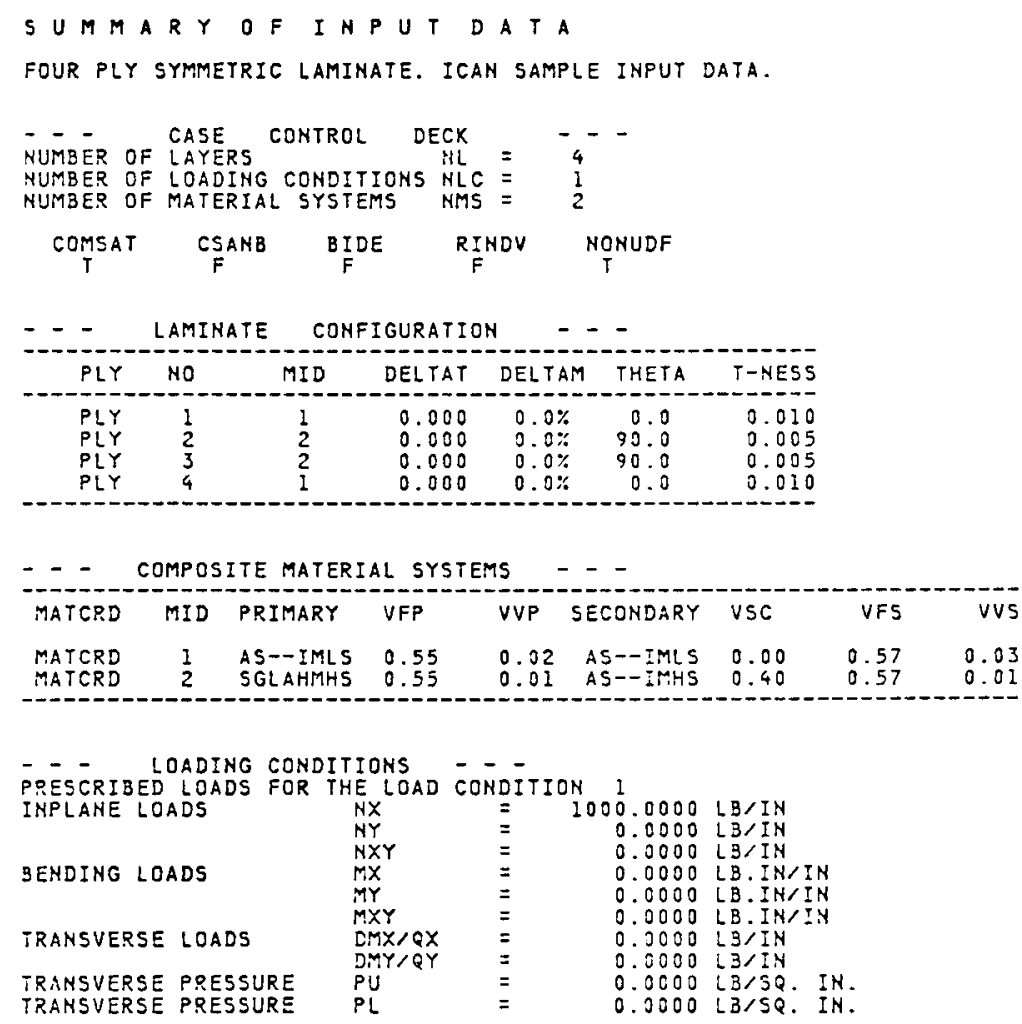

(B) SUMHARY OF INPUT DATA.

FIGURE 2. - INTEGRATED COMPOSITE ANALYZER (ICAM). 


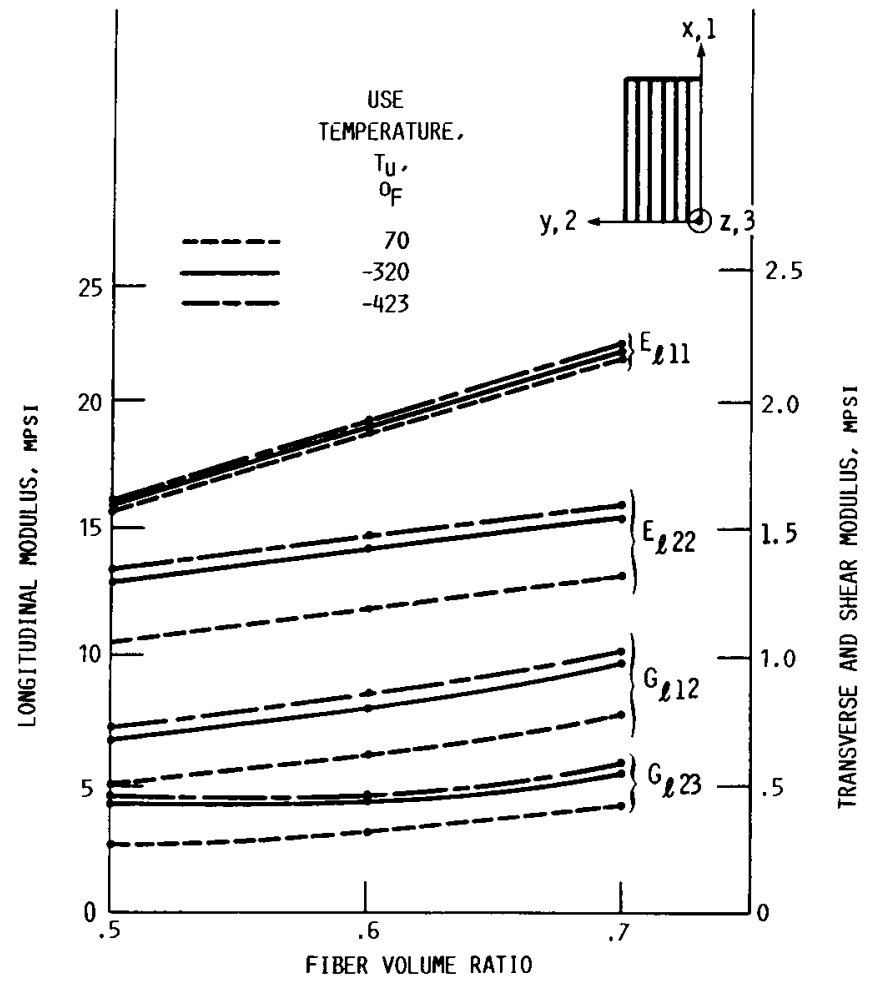

(A) MODULI.

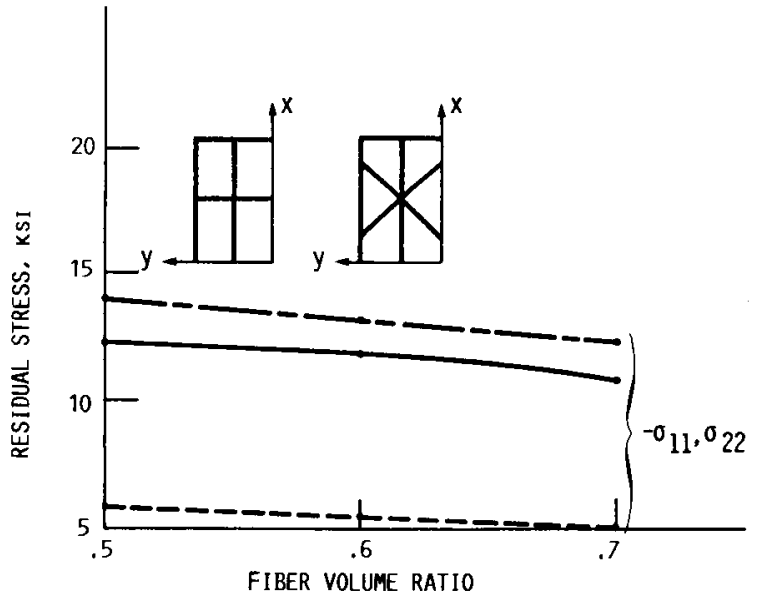

(B) RESIDUAL STRESSES. CURE TEMPERATURE, $370^{\circ} \mathrm{F}$.

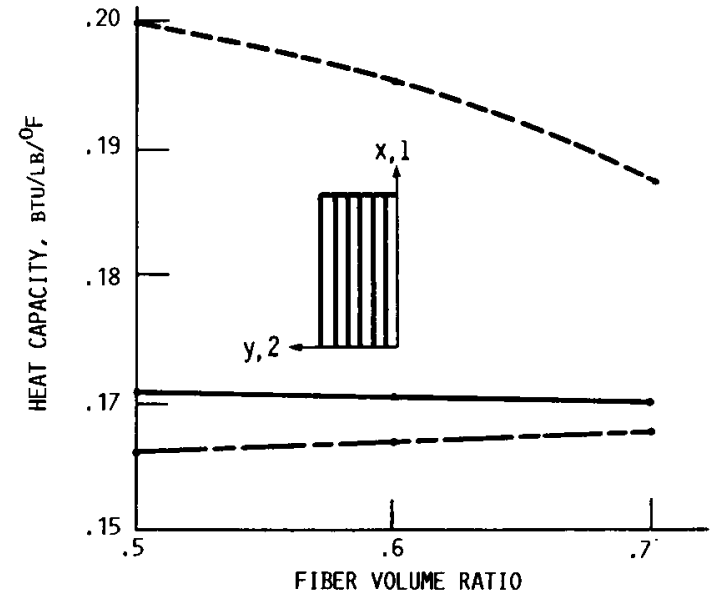

(C) HEAT CAPACITY.

FIGURE 3. - COMPOSITE PROPERTIES IN SPACE ENVIRONMENTS AS PREDICTED BY ICAN FOR GRAPHITE/EPOXY. 


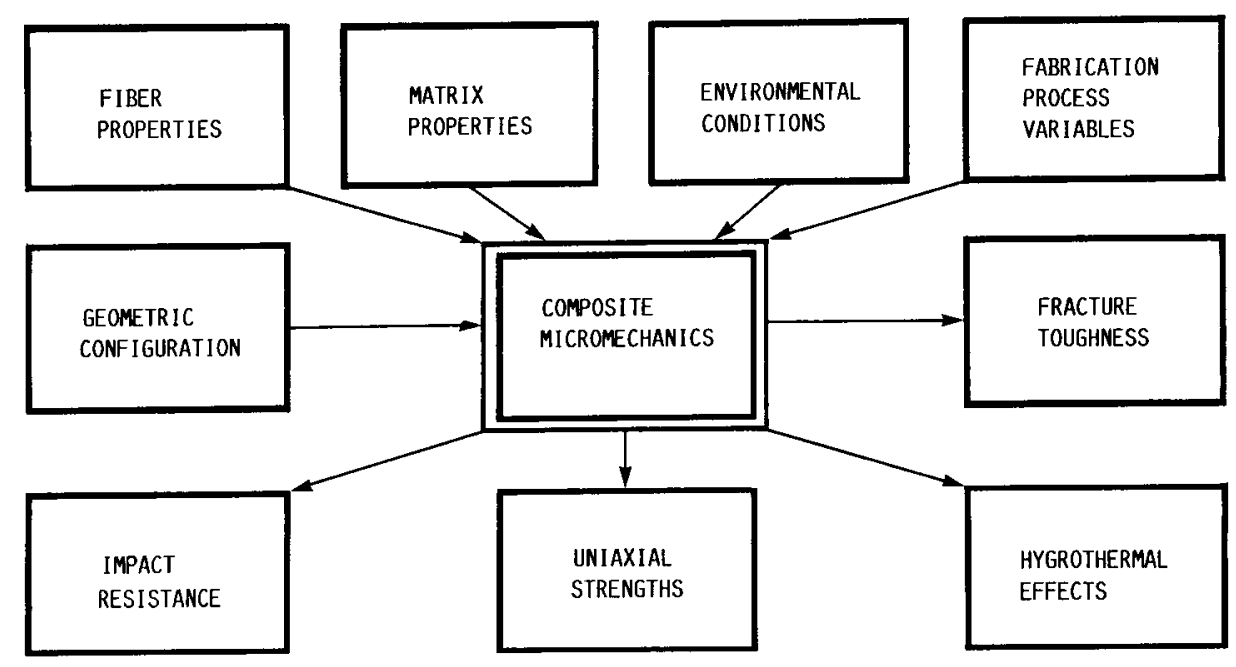

(A) BLOCK DIAGRAM.

1. LONGITUDinAL TENSION: $\quad S_{\ell l l 1} \approx \mathrm{k}_{\mathrm{f}} \mathrm{S}_{\mathrm{fT}}$

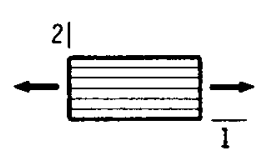

2. LONGITUDINAL COMPRESSION:

$$
\begin{array}{ll}
\text { FIBER COMPRESSION: } & \mathrm{S}_{\ell 11 C} \approx \mathrm{k}_{\mathrm{f}} \mathrm{S}_{\mathrm{fC}} \\
\text { DELAMINATION/SHEAR: } & \mathrm{S}_{\ell 11 \mathrm{C}} \approx 10 \mathrm{~S}_{\ell 12 \mathrm{~S}}+2.5 \mathrm{~S}_{\mathrm{mT}} \\
\text { MICROBUCKLING: } & \mathrm{S}_{\ell 11 \mathrm{C}} \approx \frac{\mathrm{G}_{\mathrm{m}}}{1-\mathrm{k}_{\mathrm{f}}\left(1-\frac{\mathrm{G}_{\mathrm{m}}}{\mathrm{G}_{\mathrm{f} 12}}\right)}
\end{array}
$$

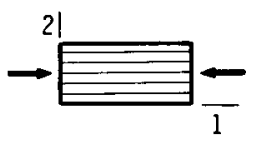

3. TRANSVERSE TENSION:

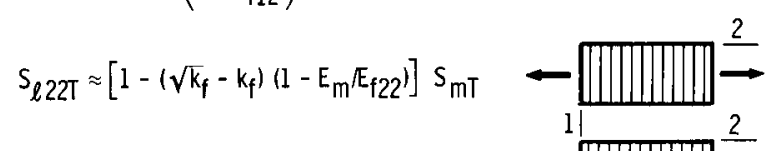

4. TRANSVERSE COMPRESSION:

$$
S_{\ell 22 C} \approx\left[1-\left(\sqrt{k_{f}}-k_{f}\right)\left(1-E_{m} / E_{f 22}\right)\right] S_{m C}
$$

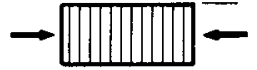

5. INTRALAMINAR SHEAR:

$S_{\ell 12 S} \approx\left[1-\left(\sqrt{k_{f}}-K_{f}\right)\left(1-G_{m} / G_{f 12}\right)\right] S_{m S}$

6. FOR VOIDS:

$$
S_{m} \approx\left\{1-\left[4 k_{v} /\left(1-k_{f} / \pi\right]^{1 / 2}\right\} S_{m}\right.
$$

$$
\text { VOID }-{ }^{0} 0_{0}^{\circ} 0_{0}^{0}
$$

(B) UNIAXIAL STRENGTHS, IN-PLANE.

FIGURE 4. - SIMPLIFIED COMPOSITE MICROMECHANICS EQUATIONS FOR STRENGTH. 
1. INTERLAMINAR SheAR: $S_{\ell 135} \approx\left[1-\left(\sqrt{k_{f}}-k_{f}\right)\left(1-G_{m} / G_{f 12}\right)\right] S_{m S}$

$$
S_{\ell 23 S} \approx\left[\frac{1-\sqrt{k_{f}}\left(1-G_{m} / G_{f 23}\right)}{1-k_{f}\left(1-G_{m} / G_{f 23}\right)}\right] S_{m S}
$$

2. SHORT BEAM: SHEAR: $\quad S_{\ell 13 S B} \approx 1.5 S_{\ell 13 S}$

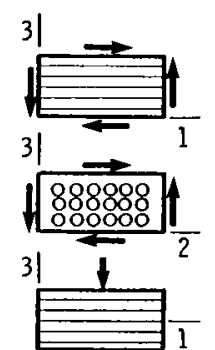

$$
\mathrm{S}_{\ell 23 \mathrm{SB}} \approx 1.5 \mathrm{~S}_{\ell 23 \mathrm{~S}}
$$

3. FLEXURAL:

$$
\begin{aligned}
& S_{\ell, 11 F} \approx \frac{3 k_{f} S_{f T}}{1+\frac{S_{f T}}{S_{f C}}} \\
& S_{\ell, 22 F} \approx \frac{3\left[1-\left(\sqrt{k_{f}}-k_{f}\right)\left(1-E_{m} / E_{f 22}\right)\right] S_{m T}}{1+\frac{S_{m T}}{S_{m C}}}
\end{aligned}
$$

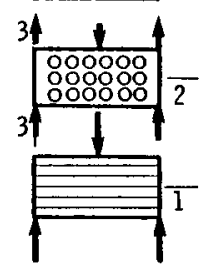

4. FOR VOIDS:

$$
S_{m} \approx\left\{1-\left[4 k_{v} /\left(1-k_{f}\right) \pi\right]^{1 / 2}\right\} S_{m}
$$

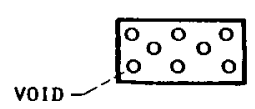

(C) UNIAXIAL STRENGTHS, THROUGH THE THICKNESS.

FIGURE 4. - CONCLUDED.
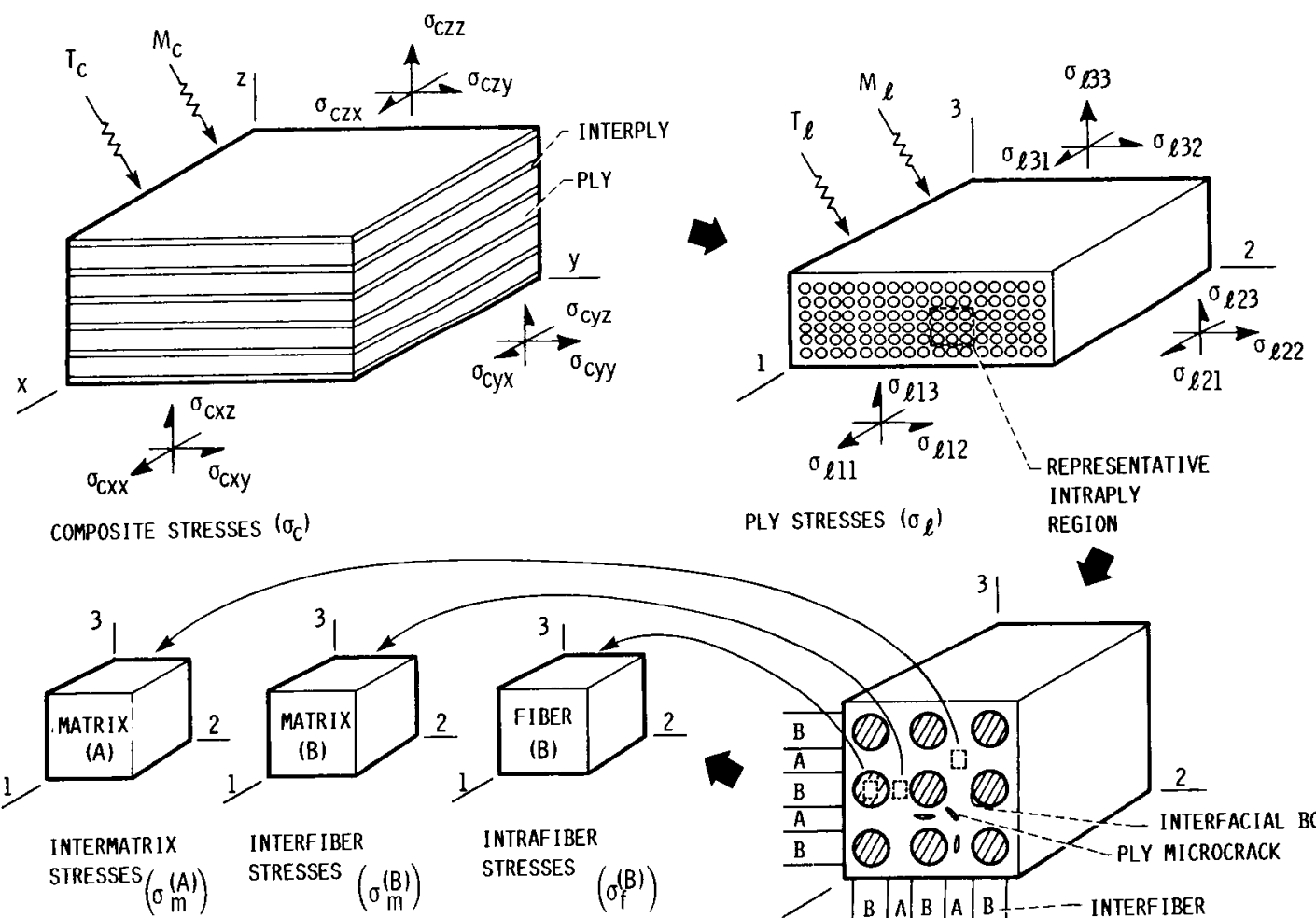

PLY STRESSES $\left(\sigma_{\ell}\right)$

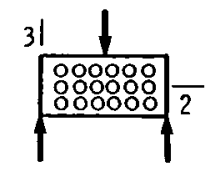




$$
\begin{aligned}
& \sigma_{m 11}=\left(\nu_{m}-\frac{\nu_{\ell 12} E_{m}}{E_{\ell 11}}\right) \sigma_{\ell 22} \\
& \sigma_{f 11}=\left(v_{f 12}-v_{\ell 12} \frac{E_{f 11}}{E_{\ell 11}}\right) \sigma_{\ell 22} \\
& \sigma_{m 22}^{(A)}=\left(E_{m} / E_{22}\right) \sigma_{\ell 22} \\
& { }_{\mathrm{m} 22}^{(\mathrm{B})}=\left(\mathrm{E}_{\ell 22} / \mathrm{E}_{22}\right)^{\sigma} \ell 22 \\
& \sigma_{f 22}^{(B)}=\left(E_{\ell 22 / E_{22}}\right)^{\sigma} \ell 22 \\
& \sigma_{m, 33}^{(A)}-\left(v_{m}-v_{\ell 23}\right)\left(E_{m} / E_{\ell 22}\right) \sigma_{\ell 22} \\
& \sigma_{m 33}^{(B)}=-\left(\frac{1-\sqrt{k_{f}}}{\sqrt{k_{f}}}\right) \sigma_{m 33}^{(A)} \\
& \sigma_{f 33}^{(B)}=-\left(\frac{1-\sqrt{k_{f}}}{\sqrt{k_{f}}}\right) \stackrel{(A)}{\sigma_{m} 33} \\
& E_{22}=\left(1-\sqrt{k_{f}}\right) E_{m}+\frac{\sqrt{k_{f}} E_{m}}{1-\sqrt{k_{f}}\left(1-\frac{E_{m}}{E_{f 22}}\right)} ; E_{\ell 22}=\frac{E_{m}}{1-\sqrt{k_{f}}\left(1-\frac{E_{m}}{E_{f 22}}\right)} \\
& v_{\ell 23}=k_{f} v_{f 23}+k_{m}\left(2 v_{m}-v_{\ell 12^{E}}{ }^{2}{ }^{2} I^{E} \ell 11\right)
\end{aligned}
$$

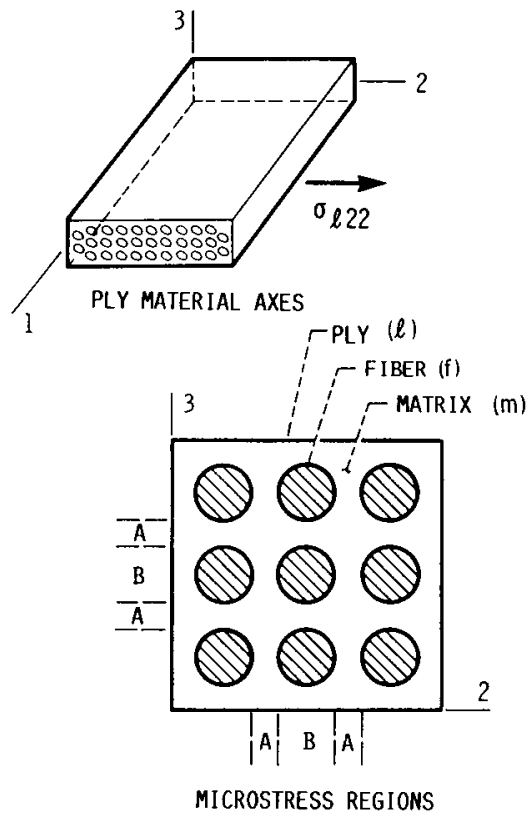

figure 6 . - equations for PLY MICROSTRESSES DUE TO PLY TRANSVERSE StRESS $\sigma_{\ell 22}$. 


\begin{tabular}{|c|c|c|}
\hline \multirow{2}{*}{$\begin{array}{l}\text { SUBREGION } \\
\text { MICROSTRESS }\end{array}$} & \multicolumn{2}{|c|}{ PLY MICROSTRESSES, KSI } \\
\hline & $\sigma_{\ell 22}=7 \mathrm{kSI}$ & $\sigma_{\ell 22}=-35 \mathrm{ksI}$ \\
\hline$\sigma_{m 11}$ & 2.4 & -12.0 \\
\hline$\sigma_{f 11}$ & -1.6 & 8.0 \\
\hline $\begin{array}{l}(A) \\
9 \pi 22\end{array}$ & 3.5 & 16.9 \\
\hline$q_{m 22}^{(B)}$ & 8.4 & -40.2 \\
\hline$\sigma_{f 22}^{(B)}$ & 8.4 & -40.2 \\
\hline$q_{m 33}^{(A)}$ & -.2 & 1.5 \\
\hline$q_{m 33}^{(B)}$ & .1 & -.4 \\
\hline$\sigma_{f 33}^{(B)}$ & .1 & -.4 \\
\hline$\sigma_{\mathrm{i} 22}^{(\mathrm{B})}$ & 8.4 & -40.2 \\
\hline$\sigma_{i 33}^{(B)}$ & .1 & -.4 \\
\hline $\begin{array}{l}(C) \\
\sigma_{i, n}\end{array}$ & 5.6 & -28.3 \\
\hline$\sigma_{i, s}^{(C)}$ & -5.8 & +28.9 \\
\hline
\end{tabular}
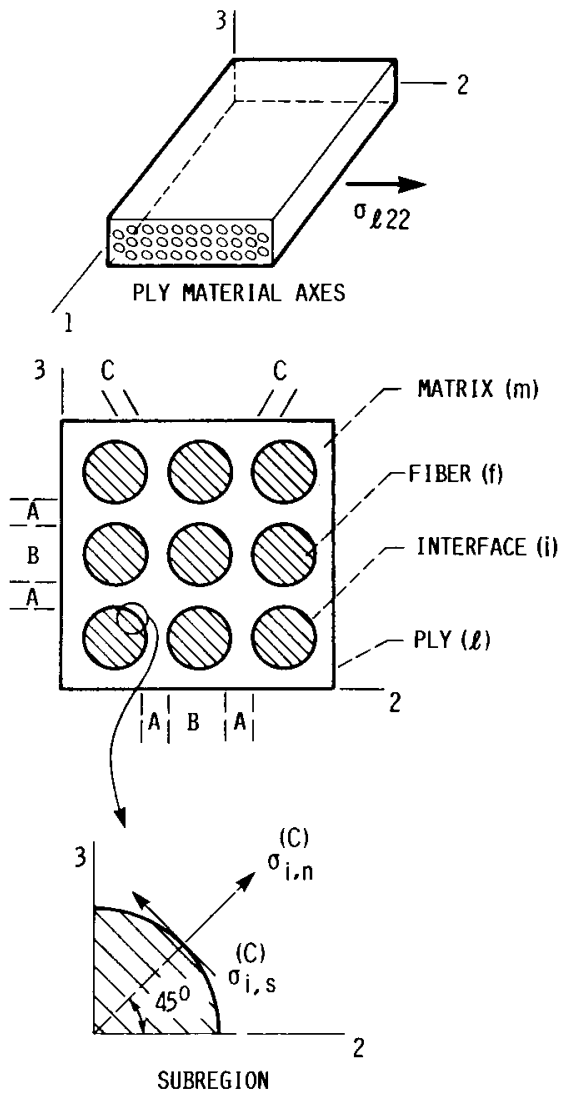

FiguRE 7. - PLY MICROSTRESSES DUE TO PLY TRANSVERSE STRESS $\sigma_{\ell 22}$.

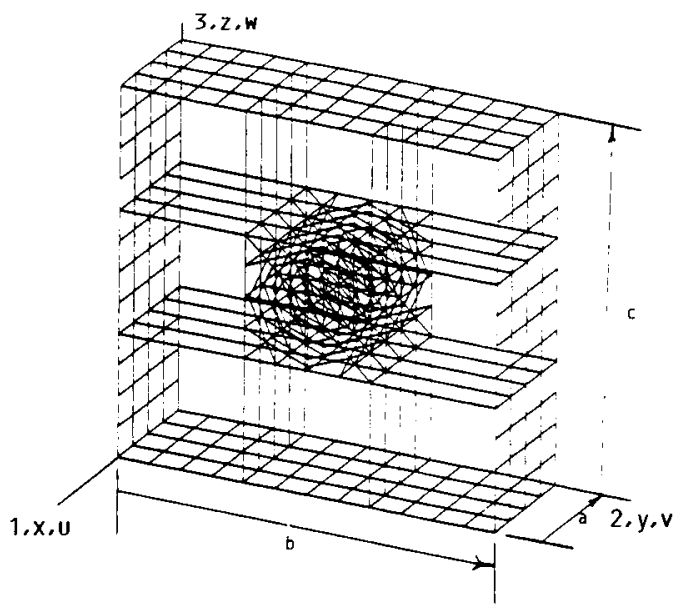

(A) NINE-CELL SUPERELEMENT MODEL (896 ELEMENTS, 1034 NODE POINTS).

FIGURE 8. - MICROMECHANICS THREE-DIMENSIONAL FINITEELEMENT CORRELATIONS FOR UNIDIRECTIONAL COMPOSITES (AS GRAPHITE-FIBER-EPOXY MATRIX). 


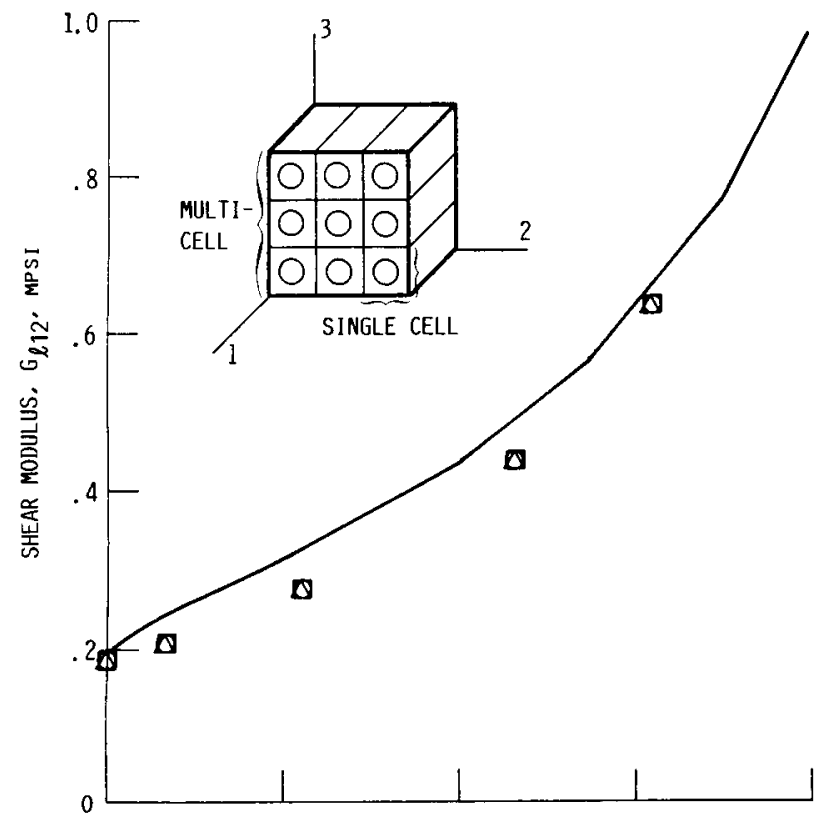

(B) SHEAR MODULUS $G_{\ell 12}$

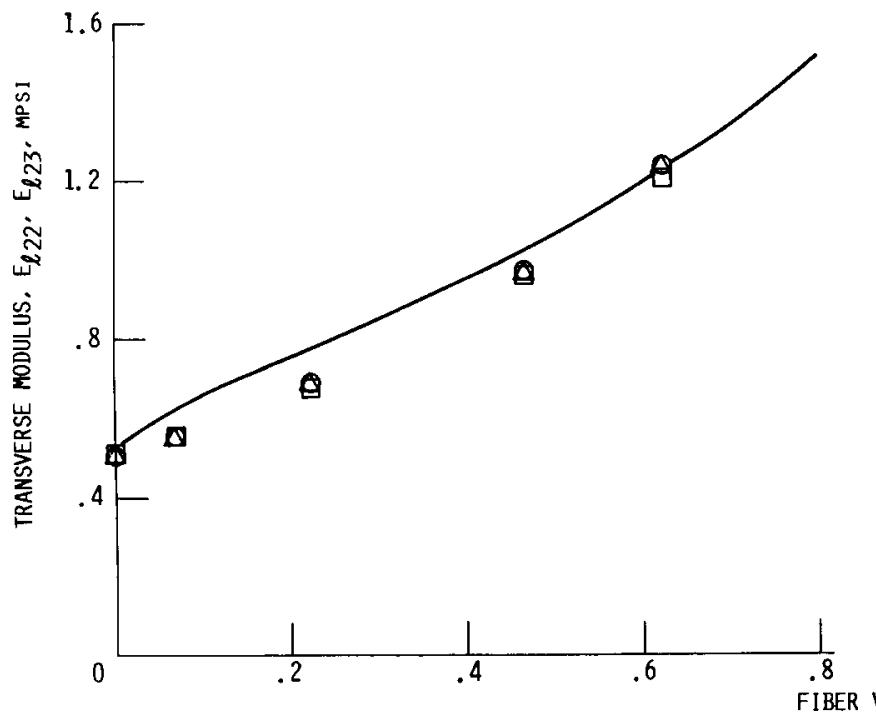

(D) TRANSVERSE MODULUS.

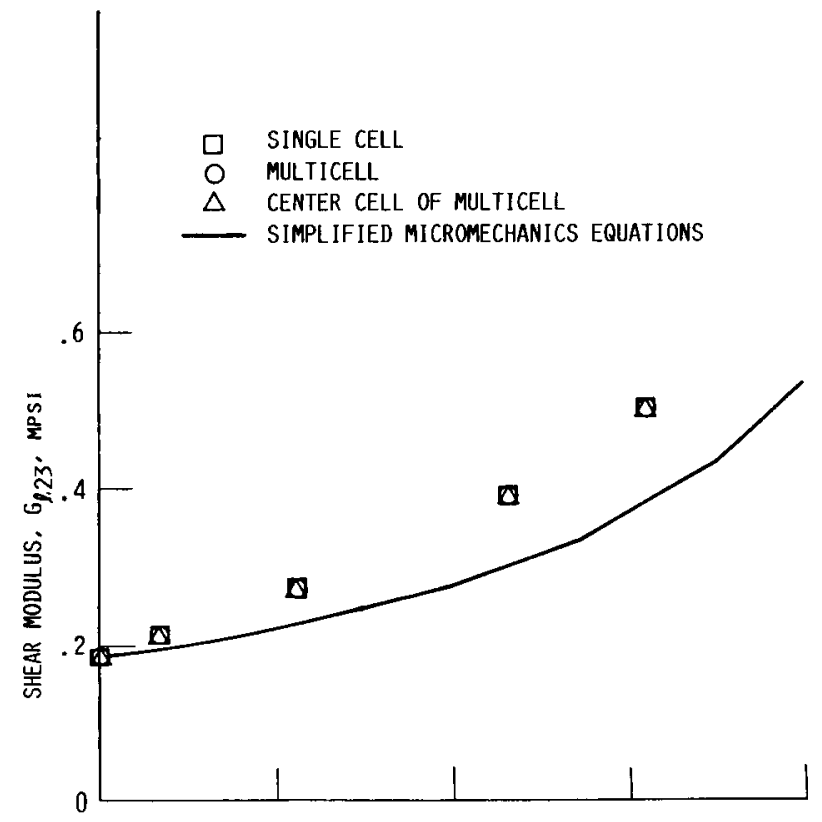

(C) SHEAR MODULUS $G_{\ell 23}$.

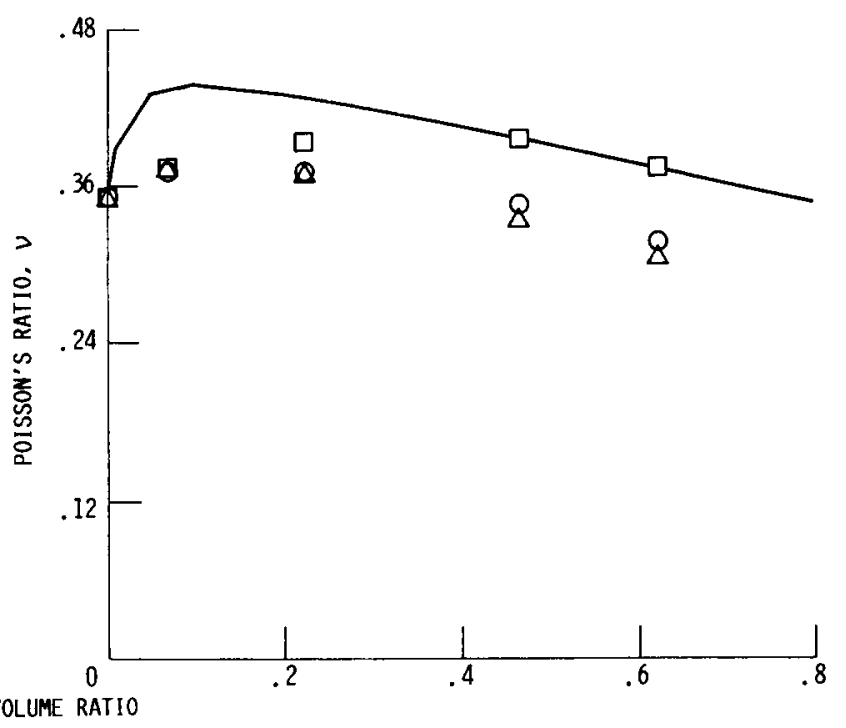

(E) POISSON'S RATIO.

FIGURE 8. - CONCLUDED. 


\section{ORTGNAL PACE IS \\ OF PO, …}

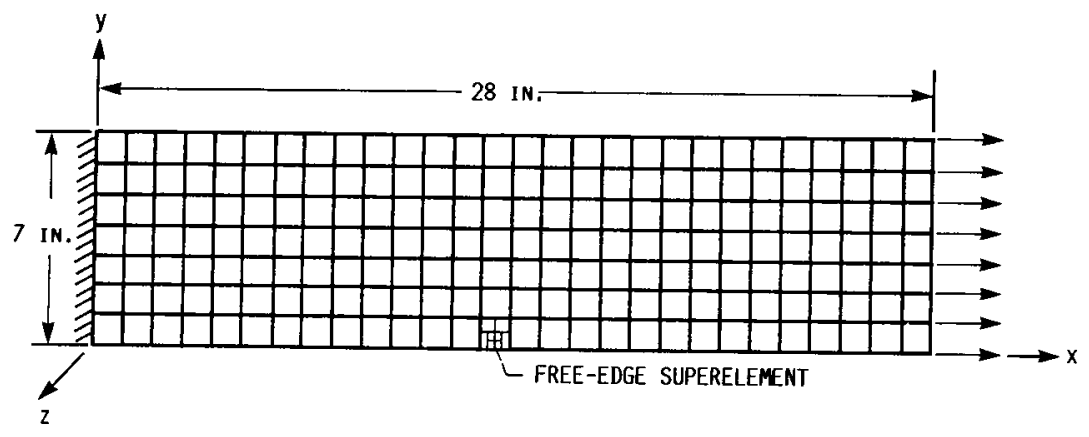

(A) FINITE-ELEMENT MODEL.

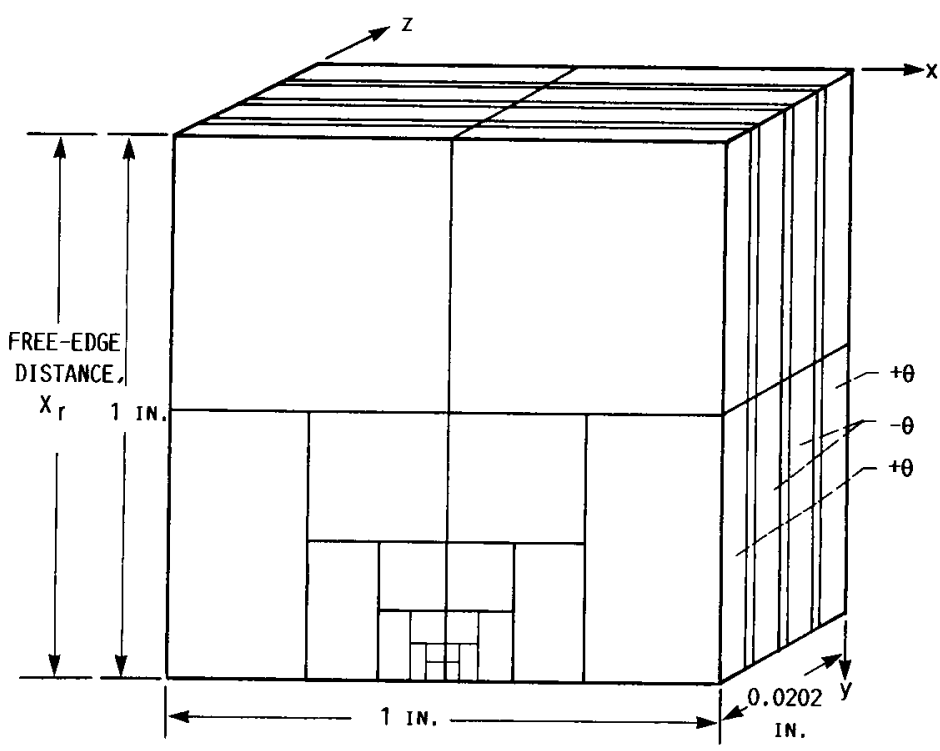

(B) FREE-EDGE SUPERELEMENT.

FIGURE 9. - FINITE-ELEMENT SUBSTRUCTURING. 

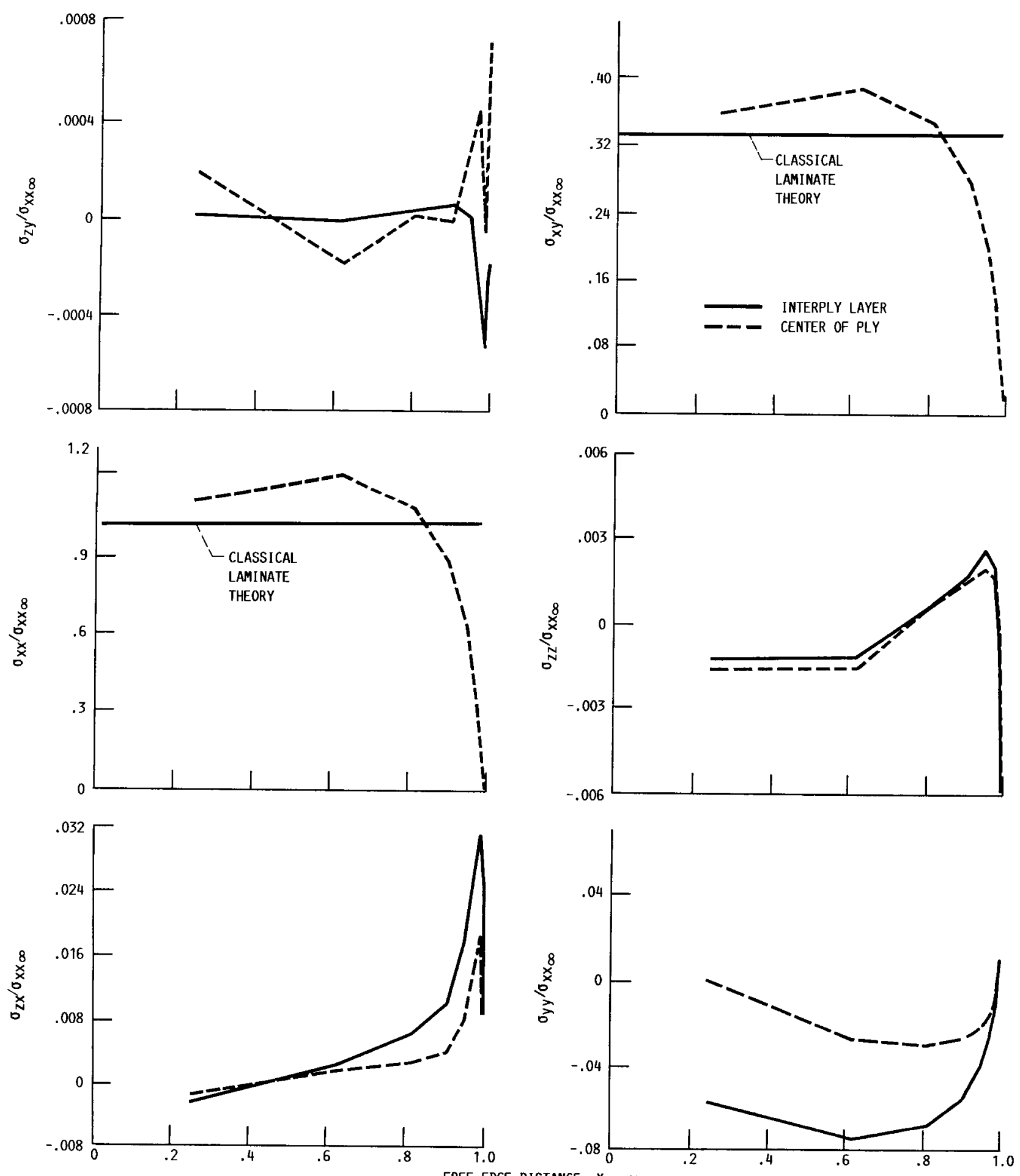
(C) THREE-DIMENSIONAL AND INTERPLY STRESS FIELDS AS THE FREE EDGE IS APPROACHED ( $20^{\circ}$ PLY, $[ \pm 20]_{s}$ AS GRAPH 1 TE-FIBER/
EPOXY LAMINATE).

FIGURE 9. - CONCLUDED. 
(1) DETERMINE REQUISITE PROPERTIES AT DESIRED CONDITIONS USING COMPOSITE MICROMECHANICS.

(2) RUM THREE-DIMENSIONAL FINITE-ELEMENT ANALYSIS

ON ENF (MFF) SPECIMEN FOR AN ARBITRARY LOAD.

(3) SCALE LOAD TO MAICH INTERLAMINARY SHEAR STRESS AT ELEMENT MEXT TO CRACK TIP.

(4) WITH SCALED LOAD. EXTEND CRACK AND PLOT STRAIN ENERGY RELEASE RATE AS A FUNCTION OF CRACK LENGTH.

(5) SELECT CRITICAL STRAIN ENERGY RELEASE RATE AND CRACK LENGTH.

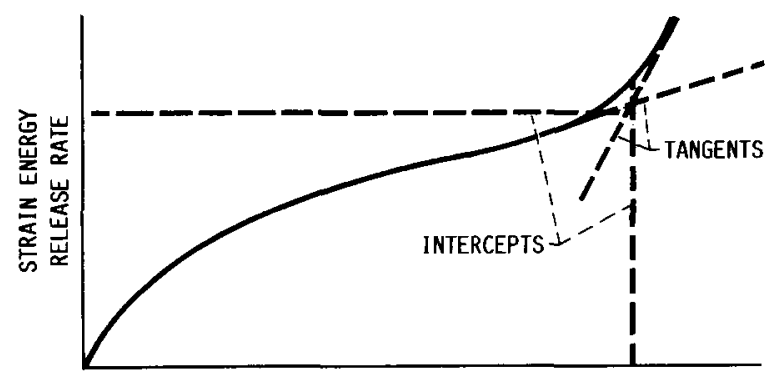

EXTENDED CRACK LENGTH, a

FIGURE 10. - GENERAL PROCEDURE FOR PREDICTING COMPOSITE INIERLAMIMAR FRACTURE TOUGHNESS BY USING END-NOTCHFLEXURE (ENF) OR MIXED-MODE-FLEXURE (MFF) METHOD.

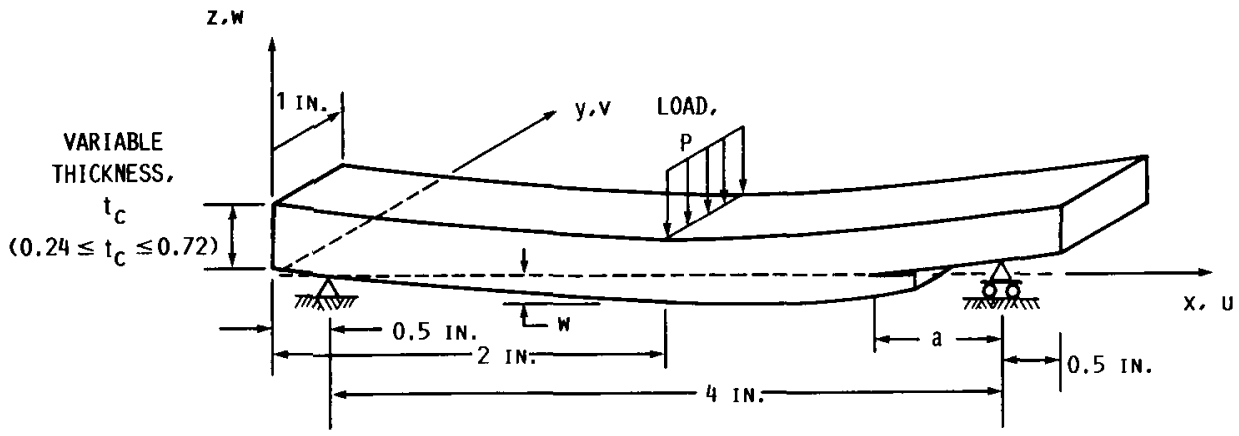

FIGURE 11. - COMPONENT GEOMETRY AND LOADING SCHEMATIC. 


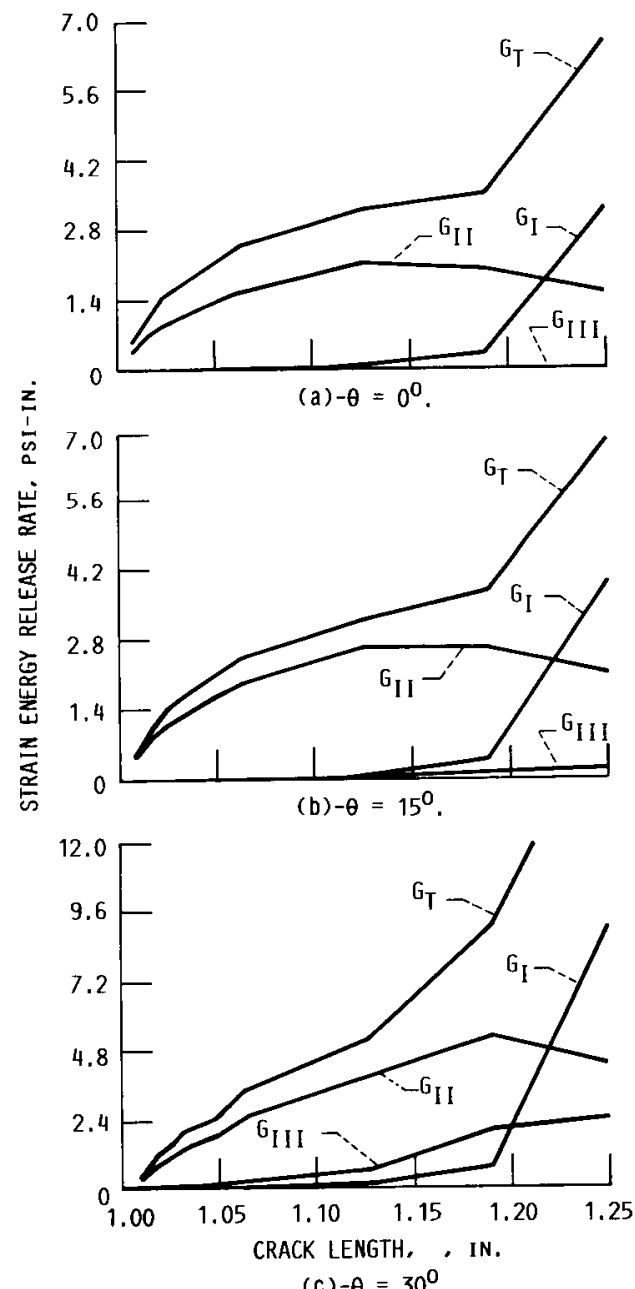

(C) $-\theta=30^{\circ}$.

FIGURE 12. - STRAIN ENERGY RELEASE RATES FOR DIFFERENT PLY ORIENTATIONS ( $\left(-\theta_{36}{ }^{\prime}\right.$ $\left.\left.+\theta_{12}\right) ; 0^{\circ} \leq \theta \leq 30^{\circ}\right)$; AS GRAPHITEFIBER/EPOXY. 


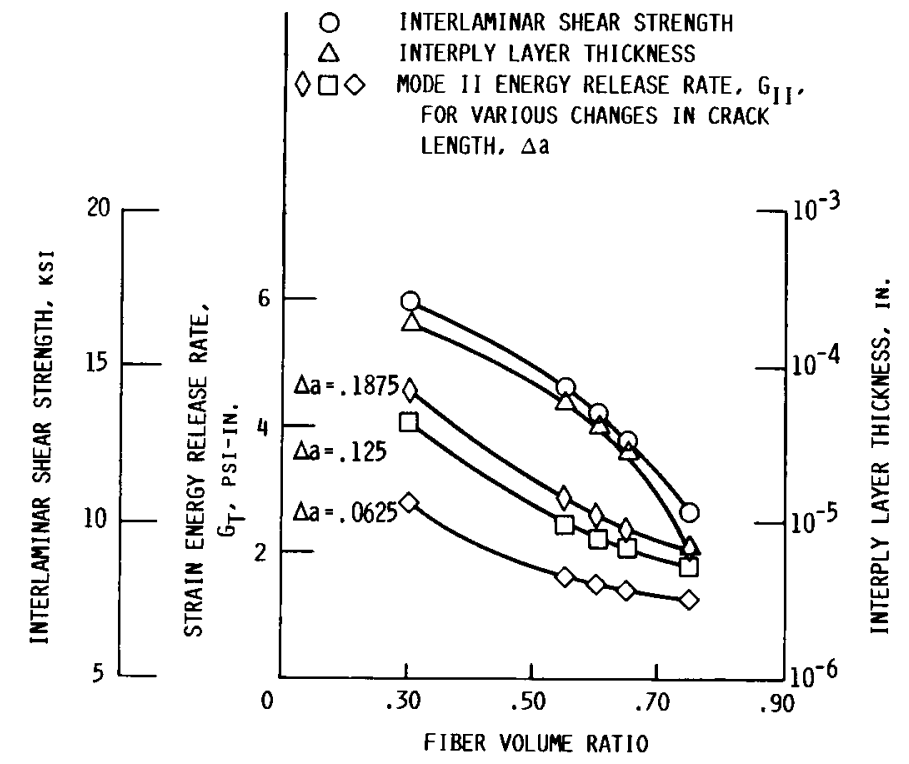

FIGURE 13. - FIBER VOLUME RATIO EFFECT ON INTERLAMINAR FRACTURE TOUGHNESS PARAMETERS. END-NOTCH FLEXURE (AS GRAPHITE-FIBER/EPOXY).

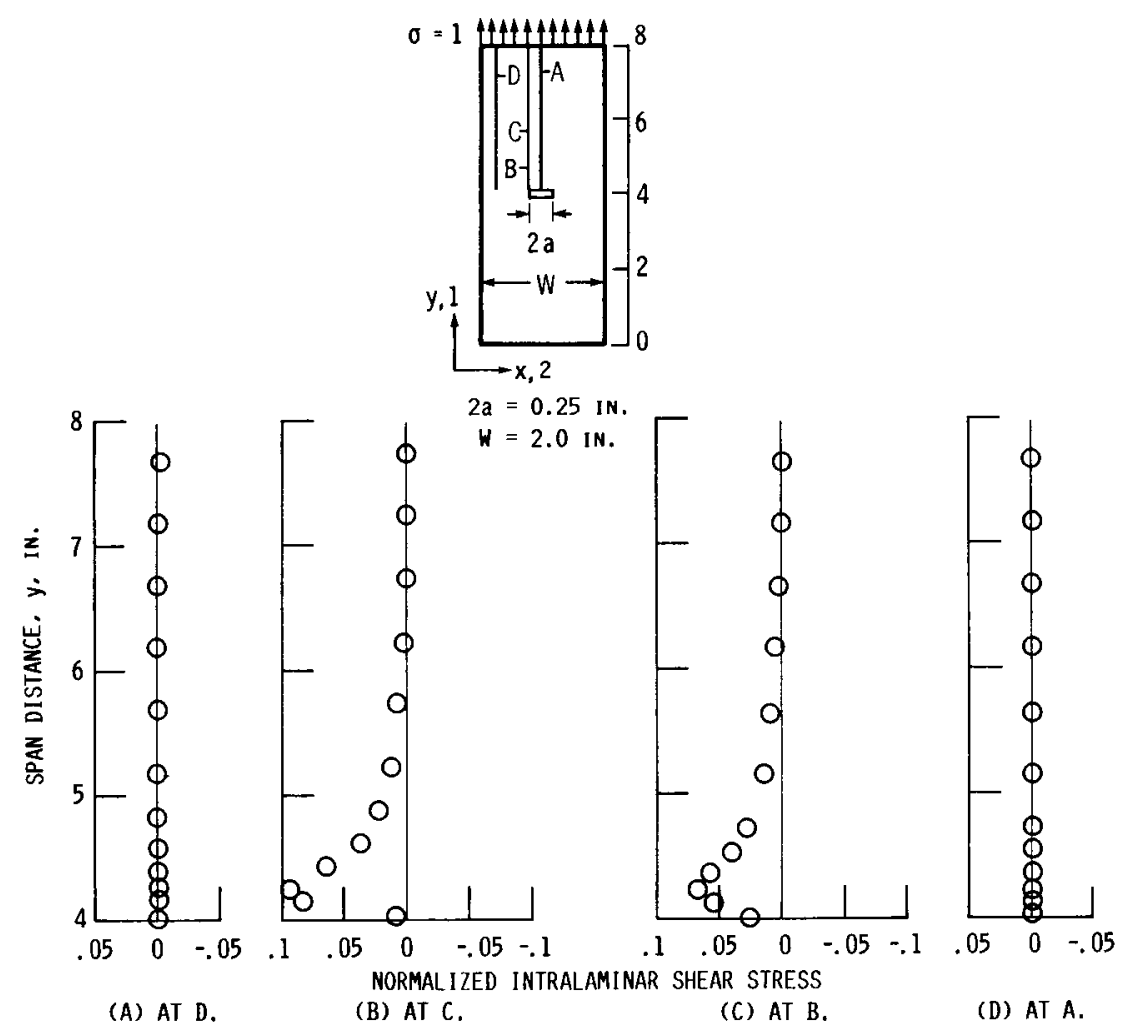

FIGURE 14. - MAGNITUDE PROFILES FOR PLY INTRALAMINAR SHEAR STRESS $\sigma_{12}$ IN UNIDIRECTIONAL GRAPHITE/EPOXY (T300/934) COMPOSITE WITH CENTERED THROUGH-SLIT, AT VARIOUS LOCATIONS SHOWN ON SKETCH. 


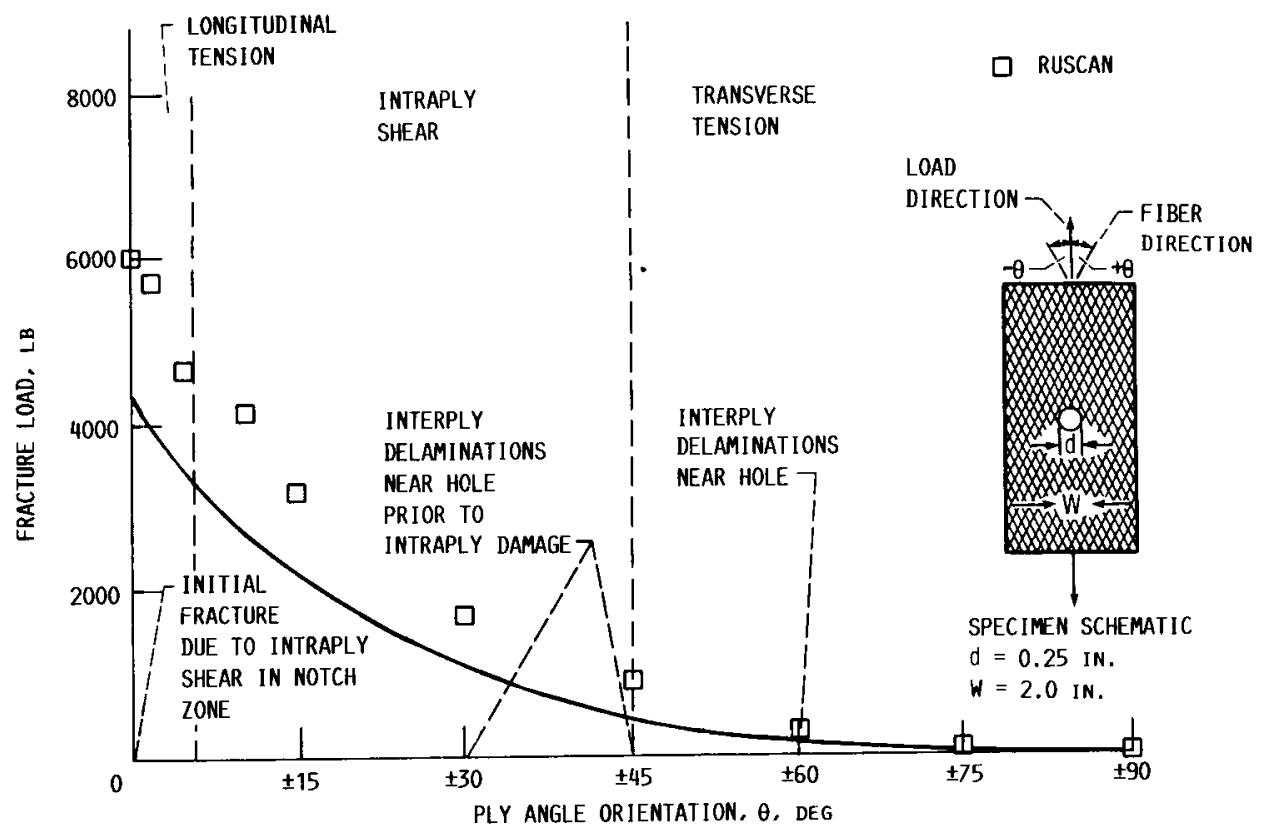

FIgURE 15. - PREDOMINANT FRACTURE MODES IN NOTCHED LAMINATE WITH THROUGH-HOLE. PRESENCE OF INITIAL OR SECONDARY MODE IS INDICATED FOR INDIVIDUAL ANGLEPLY. 


\section{GRIGINAL PAGE IS \\ DF PO}

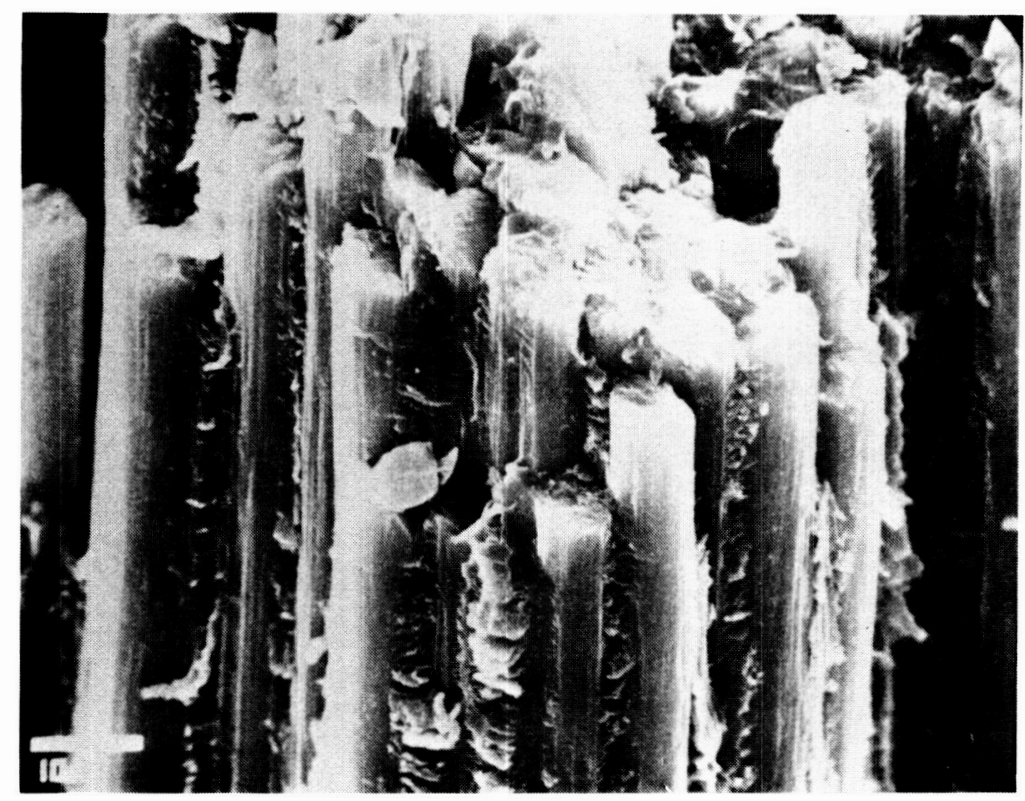

ORVGINAL PAGE IS
OE POOR QUALITY

(A) $[ \pm 15]$ S LAMINATE.

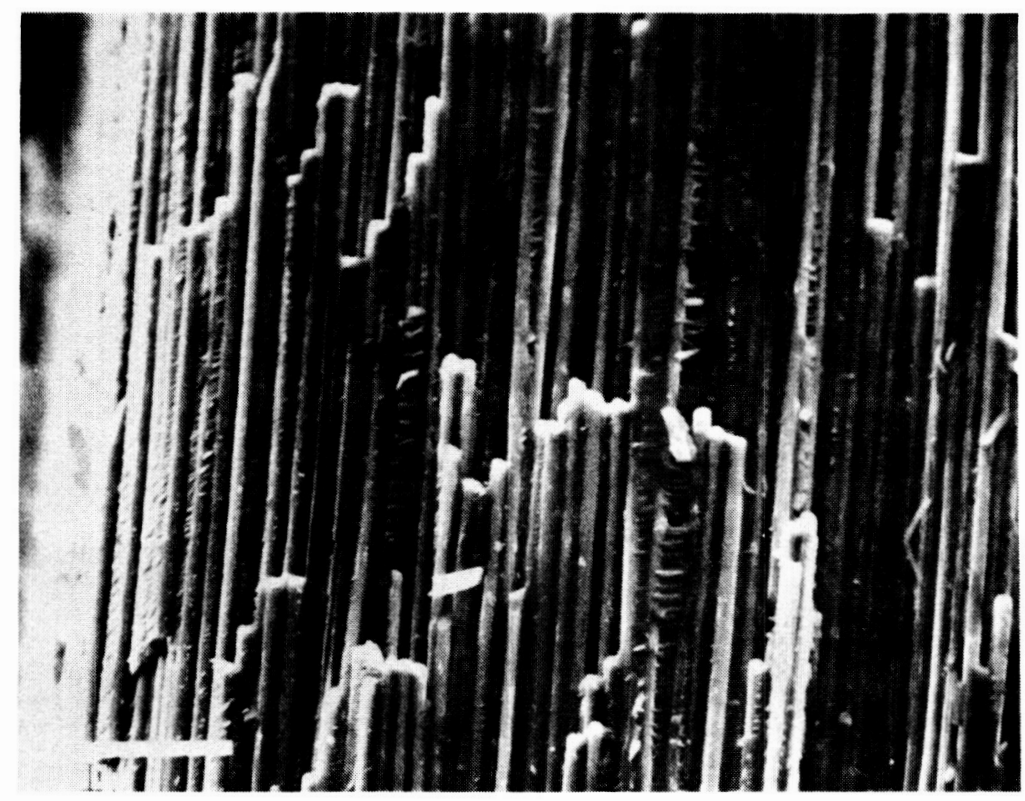

(B) $[ \pm 45]_{S}$ LAMINATE.

FIGURE 16. - PHOTOMICROGRAPHS OF FRACTURE SURFACES SHOWING MATRIX HACKLES AS

DOMINANT MICROSTRUCTURAL CHARACTERISTIC INDICATIVE OF INTRAPLY SHEARING MODE. 


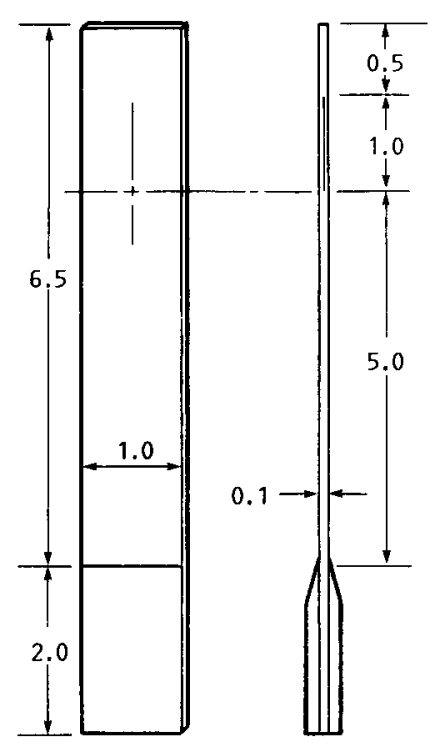

(A) IMPACT SPECIMEN GEOMETRY. (ALL DIMENSIONS IN INCHES.)

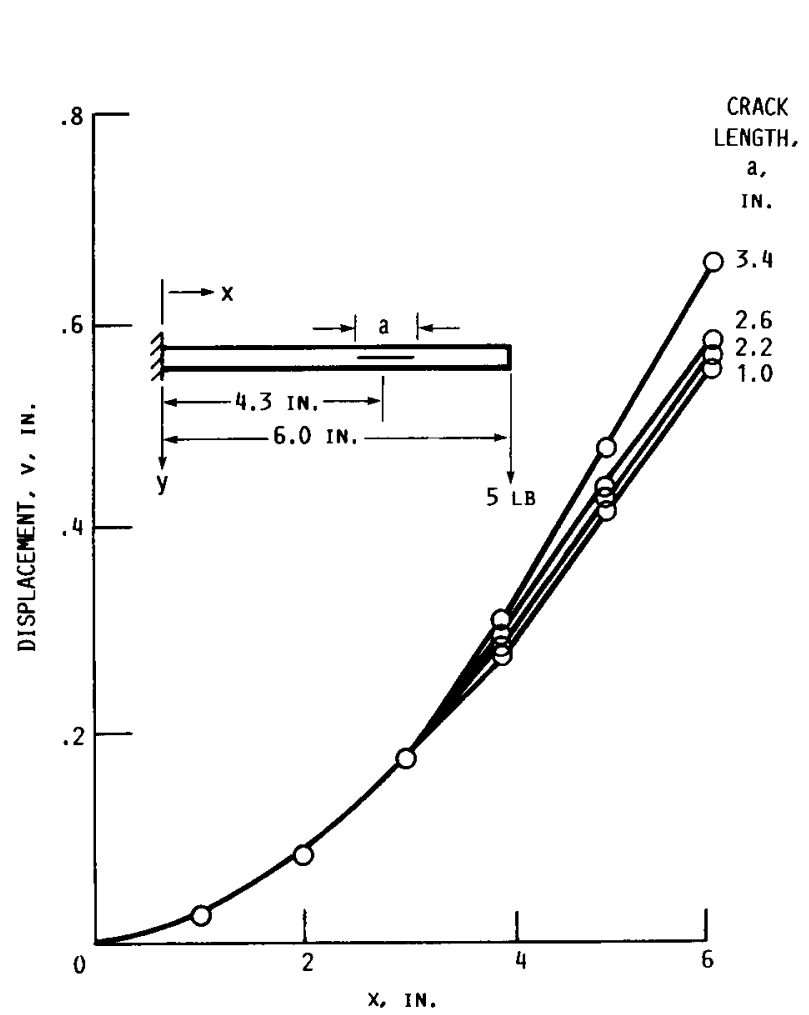

(B) DISPLACEMENT.

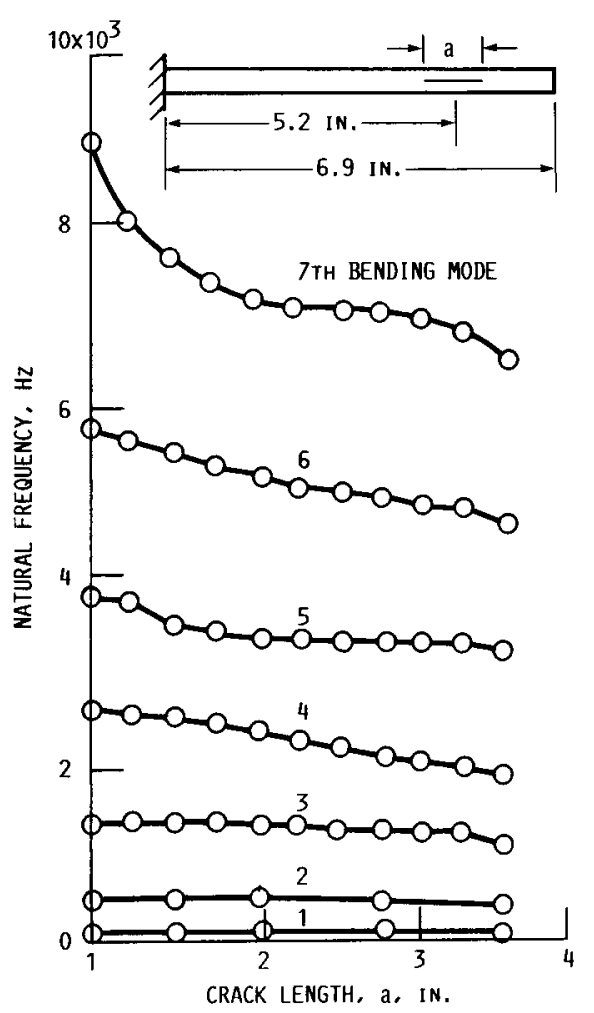

(C) FREQUENCY.

FigURE 17. - DELAMINATION EFFECTS ON DISPLACEMENT AND FREQUENCY. 


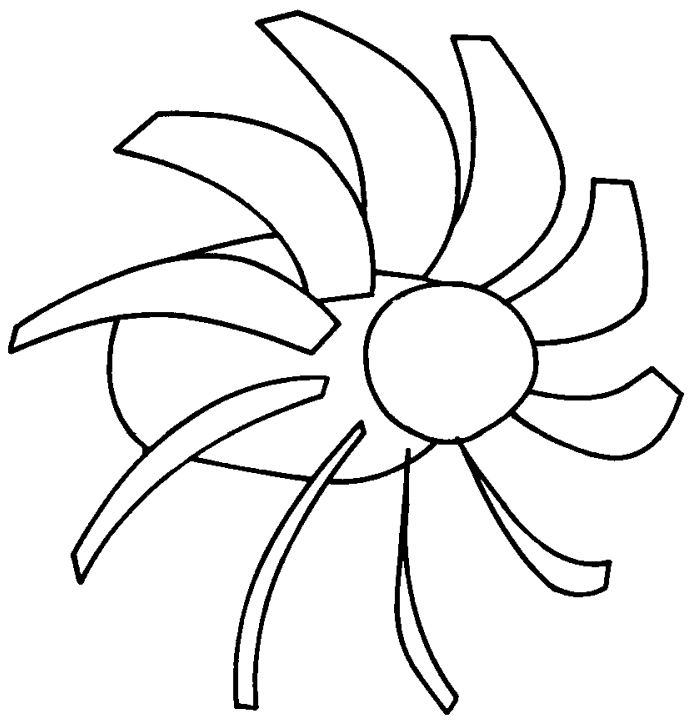

(A) TURBOPROP,

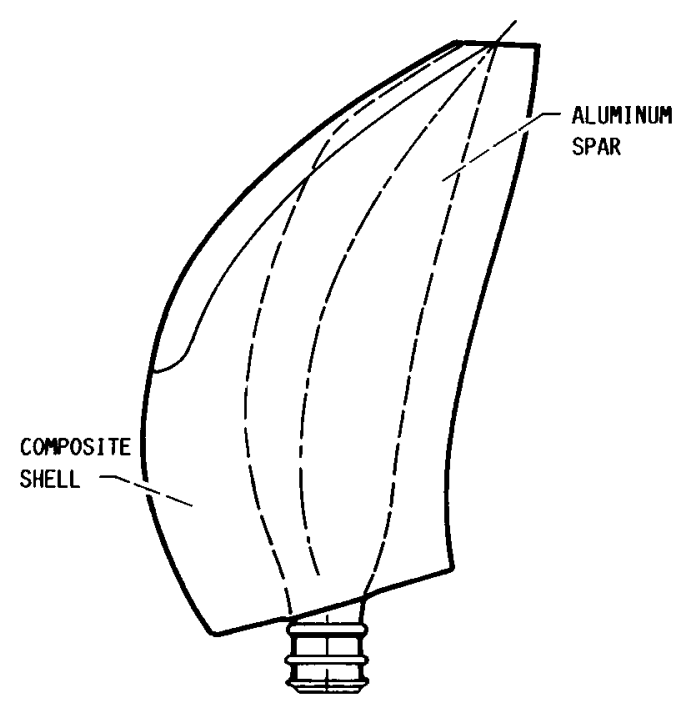

(B) PROPELLER BLADE.

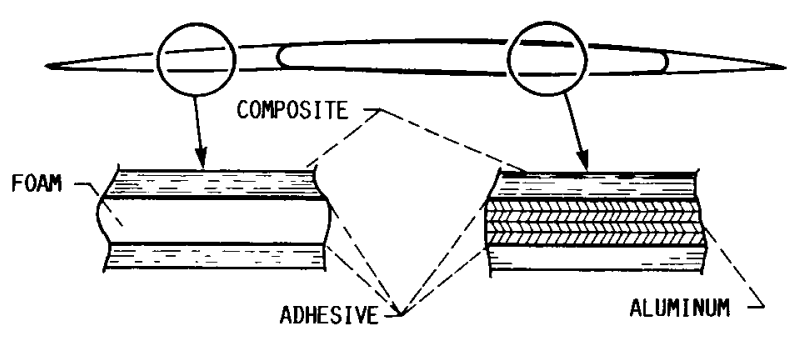

(C) BLADE INTERNAL STRUCTURE.

FIGURE 18. - COMPOSITE TURBOPROP AND BLADE STRUCTURE. 
(1) APPROXIMATE ANALYSES

(a) CENTRAL PROCESSING UNIT (CPU) EFFICIENT

(b) CAPTURE IMPORTANT STRUCTURAL INTERACTIONS

(2) REFINED ANALYSES
(a) CPU INTENSIVE
(b) DETAILED ANALYSIS

(3) ANALYSIS RECALIBRATION

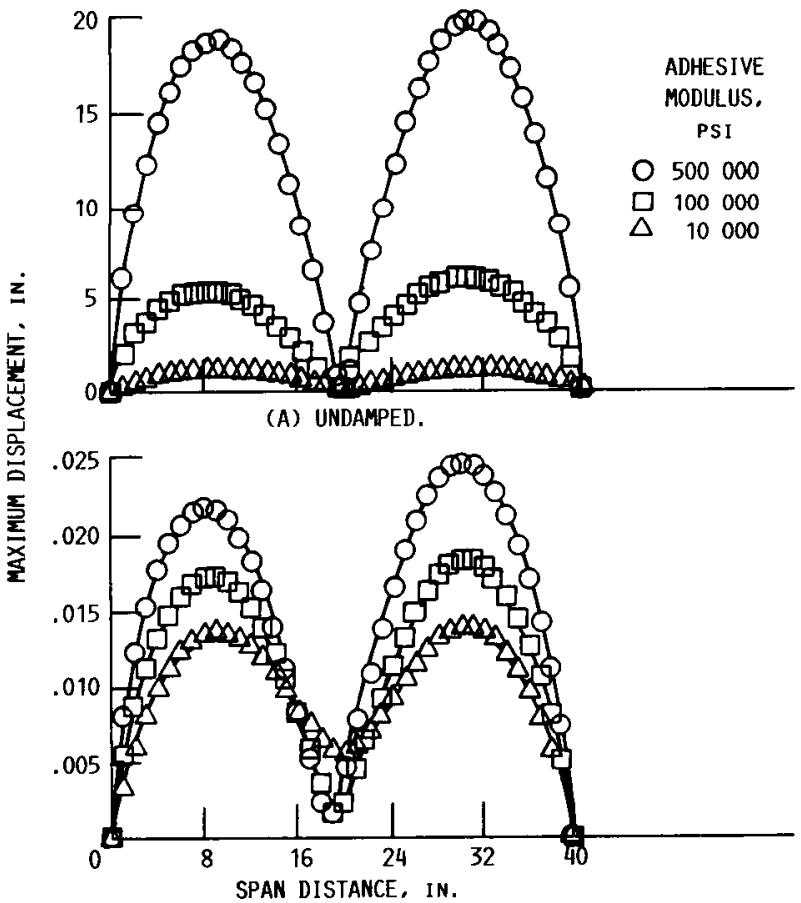

(a) MODIFY CONSTRAINT LIMITS

(b) MODIFY APPROXIMATE ANALYSES

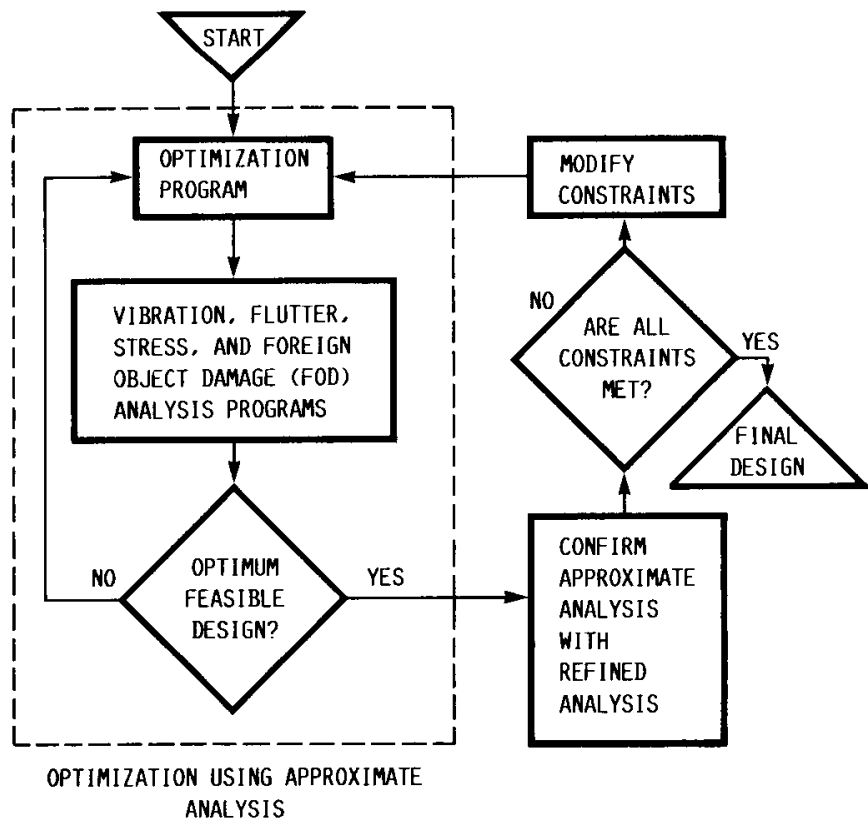

FIGURE 20. - TAILORING PROCEDURE USING APPROXIMATE AND REFINED BLADE ANALYSES. STRUCTURAL TAILORING OF COMPOSITE BLADES (STAEBL). 
(1) DESIGN VARIATIONS REFLECTED BY SCALING BLADE COORDINATES

(2) BLADE MESH IS GENERATED INSIDE STAEBL

(3) EQUIVALENT COMPOSITE MATERIAL PROPERTIES OBTAINED USING LAMINATION THEORY

(4) AUTOMATIC IN-PLANE ROTATION SUPPRESSION

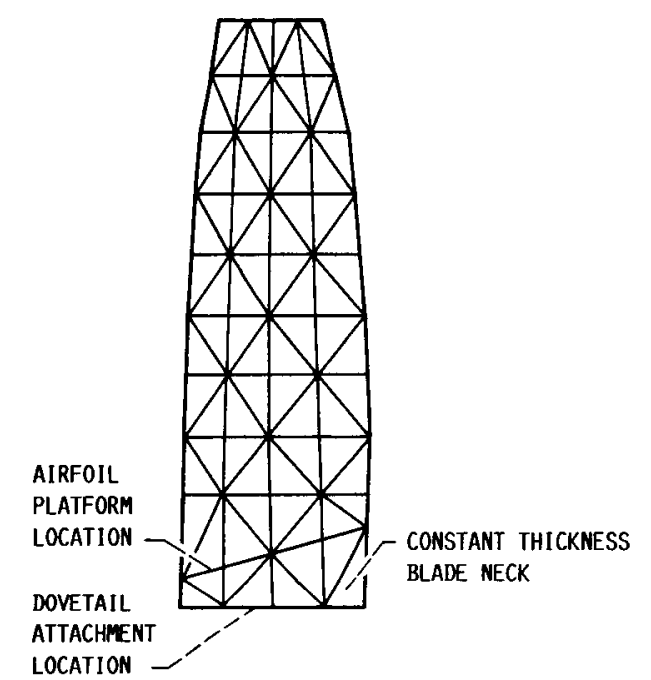

FIGURE 21. - DEDICATED FINITE-ELEMENT BLADE MESH GENERATOR. STRUCTURAL TAILORING OF COMPOSITE BLADES (STAEBL). 


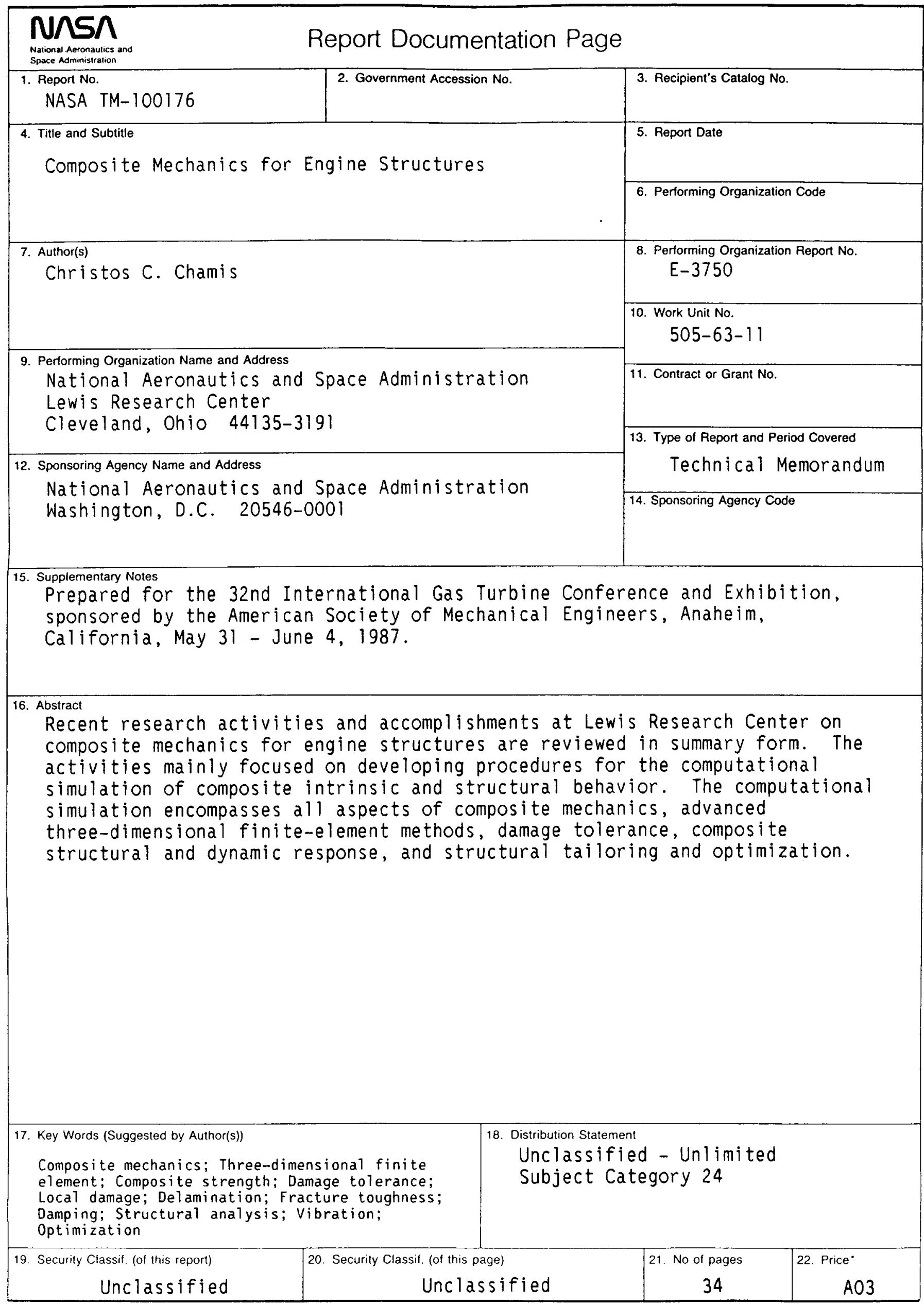

